\title{
Doublecortin (Dcx) Family Proteins Regulate Filamentous Actin Structure in Developing Neurons
}

\author{
Xiaoqin Fu, ${ }^{1}$ Kristy J. Brown, ${ }^{2}$ Chan Choo Yap, ${ }^{3}$ Bettina Winckler, ${ }^{3}$ Jyoti K. Jaiswal, ${ }^{2}$ and Judy S. Liu ${ }^{1}$ \\ ${ }^{1}$ Center for Neuroscience Research and ${ }^{2}$ Center for Genetic Medicine Research, Children's National Medical Center, Washington, DC 20010, and \\ ${ }^{3}$ Department of Neuroscience, University of Virginia Medical School, Charlottesville, Virginia 22908
}

Doublecortin (Dcx) is the causative gene for X-linked lissencephaly, which encodes a microtubule-binding protein. Axon tracts are abnormal in both affected individuals and in animal models. To determine the reason for the axon tract defect, we performed a semiquantitative proteomic analysis of the corpus callosum in mice mutant for Dcx. In axons from mice mutant for Dcx, widespread differences are found in actin-associated proteins as compared with wild-type axons. Decreases in actin-binding proteins $\alpha$-actinin-1 and $\alpha$-actinin-4 and actin-related protein 2/3 complex subunit 3 (Arp3), are correlated with dysregulation in the distribution of filamentous actin (F-actin) in the mutant neurons with increased F-actin around the cell body and decreased F-actin in the neurites and growth cones. The actin distribution defect can be rescued by full-length Dcx and further enhanced by Dcx S297A, the unphosphorylatable mutant, but not with the truncation mutant of Dcx missing the C-terminal S/P-rich domain. Thus, the C-terminal region of Dcx dynamically regulates formation of F-actin features in developing neurons, likely through interaction with spinophilin, but not through $\alpha$-actinin-4 or Arp3. We show with that the phenotype of Dcx/Doublecortin-like kinase 1 deficiency is consistent with actin defect, as these axons are selectively deficient in axon guidance, but not elongation.

\section{Introduction}

Defects in axonal tracts are frequently observed due the advent of modern neuroimaging and are associated with a number of neurological and psychiatric disorders, including autism, epilepsy, and schizophrenia. Thinning or agenesis of the corpus callosum is observed in diseases including seizure disorders and in patients with autism spectrum disorders (Vidal et al., 2006; Stevanin et al., 2007). Single gene disorders have also been associated with malformation of axon tracts. Axonal defects in all of these disorders are thought to arise from problems with the developmental program of axons; however, little is known of the complex pathogenesis of defects in axon growth and guidance.

Mutations in a gene encoding an unusual microtubuleassociated protein (MAP), doublecortin (Dcx), cause a neuronal migration disorder, lissencephaly, leading to intellectual disability and epilepsy (des Portes et al., 1998; Gleeson et al., 1998). Dcx and related doublecortin domain proteins, including Dclk1, have also been shown to function cooperatively in the formation of

\footnotetext{
Received Sept. 27, 2012; revised 0ct. 22, 2012; accepted 0ct. 29, 2012.

Author contributions: X.F. and J.S.L. designed research; X.F., K.J.B., J.K.J., and J.S.L. performed research; X.F., K.J.B., C.C.Y., B.W., and J.S.L. contributed unpublished reagents/analytic tools; X.F., K.J.B., J.K.J., and J.S.L. analyzed data; X.F., K.J.B., and J.S.L. wrote the paper.

J.S.L. was supported by Epilepsy Foundation and the work was made possible by NIH Core Grants NCMRR/NINDS 2R24HD050846-06 (National Center for Medical Rehabilitation Research), IDDRC 5P30HD040677-10 (Intellectual and Developmental Disabilities Research Center), and NIH NCRR UL1RR031988 (GWU-CNMC CTSI). B.W. and C.C.Y. were supported by NIH R01GM086913. We thank Molly Huntsman and Brandon Martin for their assistance.

The authors declare no competing financial interests.

Correspondence should be addressed to Judy S. Liu, Center for Neuroscience Research, Children's National Medical Center, 111 Michigan Avenue Northwest, 6th Floor M7644, Washington, DC 20010-2970. E-mail: jliu@cnmcresearch.org.

DOI:10.1523/JNEUROSCI.4603-12.2013

Copyright $\odot 2013$ the authors $\quad 0270-6474 / 13 / 330709-13 \$ 15.00 / 0$
}

long axon tracts and crossing axon tracts, including the corpus callosum (Deuel et al., 2006; Koizumi et al., 2006; Kappeler et al., 2007). However, how Dcx family proteins act during axonal tract formation is not completely understood.

Dcx-microtubule effects have been extensively studied, including recent studies showing cooperative binding effects and changes in microtubule (MT) structure, as well as regulation of molecular motors (Gleeson et al., 1999; Moores et al., 2004; Moores et al., 2006; Bechstedt and Brouhard, 2012; Liu et al., 2012). Other studies have also suggested a role for Dcx in mediating the crosstalk between the actin and microtubule cytoskeleton (Tsukada et al., 2005; Coquelle et al., 2006; Bielas et al., 2007; Santra et al., 2009). However, changes in the actin structure/ function in Dcx mutant or RNAi-treated neurons have not been previously reported, most likely because the actin phenotype is not as severe in single mutants compared with $D c x^{-/ y} ; D c l k 1^{-/-}$ neurons. Nevertheless, Dcx-actin effects may be significant for understanding the phenotype of lissencephaly.

In this study we perform a comparative proteomic analysis of an affected axon tract, the corpus callosum, to study changes in cytoskeleton proteins in the $D c x^{-/ y}$ mutant axons. Using semiquantitative proteomics we find some differences in levels of protein expression in MAPs, but comparatively greater changes in actin-associated proteins in the Dcx mutant axons. Phenotypic analysis of the $D c x / D c l k 1$ mutant neurons demonstrate changes in actin distribution, including a striking decrease of filamentous actin (F-actin) in distal neurites, including the growth cone. The small $\mathrm{C}$ terminus $\mathrm{S} / \mathrm{P}$-rich region of the Dcx protein regulates these changes in actin. Furthermore, the actin dysregulation correlates with a defect in axon guidance in these neurons. Thus, we demonstrate for the first time that Dcx has important roles, not 
only in MT function, but also in the regulation of F-actin in axonal growth cones.

\section{Materials and Methods}

Generation of $\mathrm{Dcx}^{-/ y} ; \mathrm{Dclk}^{-/-}$mutant mice. We bred $D c x^{+/-} ; D c l k^{+/-}$females with $D c l k 1^{-1-}$ males to generate $D c x^{-/ y} ; D c l k^{-/-}$ mice as described previously (Deuel et al., 2006). Animals were handled in accordance with Children's National Medical Center Institutional Animal Care and Utilization Committee-approved protocols.

Dissection and isolation of axon tracts. Wildtype and $D c x^{-/ y}$ mice at postnatal day $(\mathrm{P}) 0$ or $\mathrm{P} 2$ were perfused with saline after anesthesia. The brains were immediately dissected out from the skull and placed dorsal surface down on a nitrocellulose membrane. Coronal brain sections were cut at $500 \mu \mathrm{m}$ using the Mcllwain Tissue Chopper. Corpus callosum or anterior commissure was isolated immediately from coronal brain sections and individually flash frozen.

Mass spectrometry procedure and analysis. Proteins extracted from corpus callosum brains are separated using gradient gel electrophoresis, 4-20\% SDS-PAGE (about 30-50 mg per axon tract). Based on the staining, gels are sectioned and each band digested with trypsin and eluted as described previously (Jensen et al., 1999). Concentrated peptides from each band were injected via an autosampler $(6 \mu \mathrm{l})$ and loaded onto a Symmetry C18 trap column ( $5 \mathrm{~mm}, 300 \mu \mathrm{m}$ inner diameter $\times 23 \mathrm{~mm}$; Waters) for $10 \mathrm{~min}$ at a flow rate of $10 \mu \mathrm{l} / \mathrm{min}$, $100 \%$ in $0.1 \%$ formic acid. The sample was subsequently separated by a C18 reverse-phase column $(3.5 \mu \mathrm{m}, 75 \mathrm{~mm} \times 15 \mathrm{~cm}$, LC Packings) at a flow rate of $250 \mathrm{nl} / \mathrm{min}$ using a nanoHPLC system (Eksigent). The mobile phases consisted of water with $0.1 \%$ formic acid and $90 \%$ acetonitrile. A 65 min linear gradient from 5 to $40 \%$ acetonitrile was employed. Eluted peptides were introduced into the mass spectrometer via a $20 \mathrm{~mm}$ inner diameter, $10 \mu \mathrm{m}$ silica tip (New Objective) adapted to a nanoelectrospray source (ThermoFisher Scientific). The spray voltage was set at $1.4 \mathrm{kV}$ and the heated capillary at $200^{\circ} \mathrm{C}$. The LTQ-Orbitrap-XL (ThermoFisher Scientific) was operated in datadependent mode with dynamic exclusion in which one cycle of experiments consisted of a full-MS in the Orbitrap $(300-2000 \mathrm{~m} / \mathrm{z})$ survey scan, resolution 30,000, and five subsequent MS/MS scans in the LTQ (linear trap quadrupole) of the most intense peaks in centroid mode using collision-induced dissociation with the collision gas (helium) and normalized collision energy value set at 35\%.

Database search and label-free quantification. Mass spectral files were searched against the UniProt mouse database (UniProt release-2010_11; 16,333 entries) indexed for fully tryptic, 300-4000 mass range, and two missed cleavages using the SEQUEST algorithm in the BioWorks software package, version 3.2 (ThermoFinnigan). Mass tolerances were set for $50 \mathrm{ppm}$ error for MS and 1 Da error for MS/MS and potential modification of oxidized methionine (15.99492 Da). Search result files were uploaded to ProteoIQ label-free software, version 2.3.02, (www.bioinquire.com) for each sample, grouped as triplicates, and filtered as follows: 0.98 peptide probability, 0.95 protein probability, XCorr $>1.9$, four spectra, and two unique peptides for each protein. Scan counts were normalized based on total sample intensity. Protein fold change values were calculated by using the ratio of scan counts for each sample versus its paired control. Protein annotations were acquired using the (http://www.uniprot.org/).

Antibodies. Antisera to actin (ab8227), Dcx (ab18723), Spinophilin (ab50184), ARP4 (ab80502), Tuj1 (ab7751), Grp78 (ab21685), polyglu-
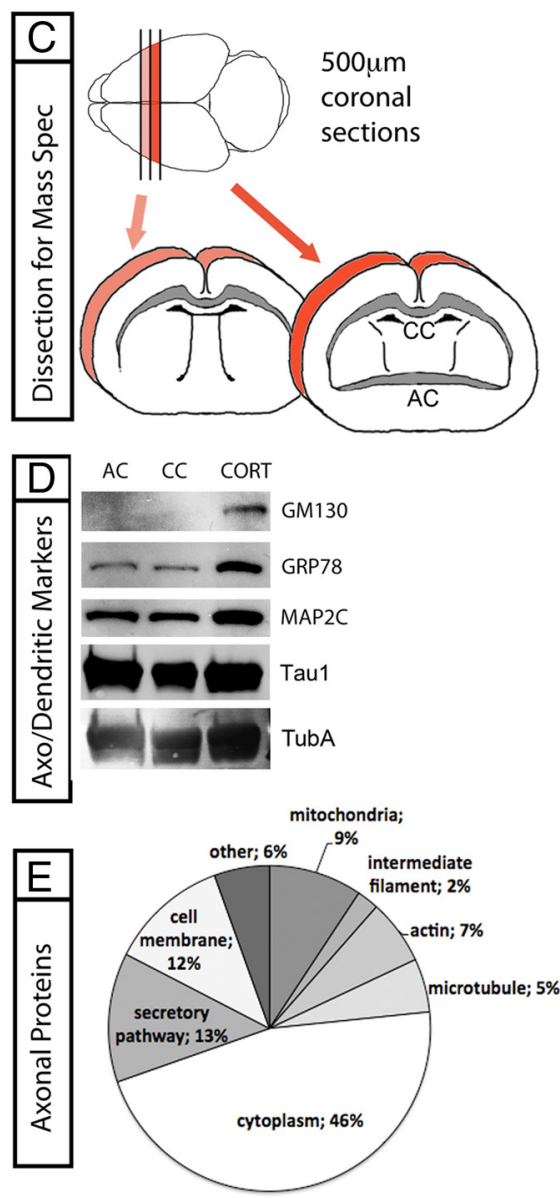

Figure 1. Axonal proteomics experiment. $A$, In comparison to wild-type mouse brain, the $D C x^{-l y} ; D c l k 1^{-1-}$ mouse brain has a marked reduction in the size of the corpus callosum (CC), hippocampal commissure (HC), and anterior commissure (AC). $\boldsymbol{B}$, The A a nalysis of cortical plate versus $C(C$ and $\mathrm{AC}$ in wild-type mice to evaluate the axonal enrichment of the $C($ dissection. $\boldsymbol{E}$, Classification of isolated proteins from mass spectrometry of CC proteins from wild-type mouse brain using the UniProt search functions.

tamylated tubulin (ab11324), acetylated alpha tubulin (ab24610), and tubulin- $\alpha$ (ab4074) were purchased from Abcam. Antiserum to Tau-1 (AB1512) was purchased from Millipore. Antiserum to ARP3 (EB06354) was purchased from Everest Biotech. Anti- $\alpha$-actinin clone EA-53 (A7732) was obtained from Sigma, and $\alpha$-actinin 4 antibody (2885-1) was obtained from Epitomics. Anti-tyrosinated tubulin antibody (302111) was from Synaptic System. Map2 (PRB-547C-100) was from Covance. Anti-GM130 (610822) was purchased from BD Transduction Laboratories.

Dissociated neuronal cultures and immunostaining. Embryonic day (E) 15 cortices or E17.5 hippocampi were dissected and dissociated using the Worthington papain dissociation system (LK003150, Worthington Biochemical). Neurons were plated on polyornithine-coated (Sigma) cover glasses, fixed in $4 \%$ paraformaldehyde, and immunostained with standard techniques and counterstained with the nuclear dye DAPI or Alexa Fluor 633 phalloidin (Invitrogen). Images were acquired using a Zeiss LSM510 line-scanning confocal microscope. For staining of permeabilized neurons, cells were permeabilized in buffer $(1 \times$ BRB80 with 1 mм EGTA, 3.7\% PFA, 0.075\% glutaraldehyde, and 0.5\% Triton X-100) for $2 \mathrm{~min}$ before fixing in $4 \%$ paraformaldehyde.

Western analysis. Standard Western analysis was performed using antibodies, as detailed above. The dual channel signal detection Odyssey system from Li-Cor was used to analyze levels over a linear dynamic range.

Dunn chamber axon guidance assay. Dissociated E17.5 cortical neuronal cells were plated (50,000 cells/coverslip) on polyornithine-coated 
Table 1. Differential expression of tubulins and microtubule-associated proteins

\begin{tabular}{|c|c|c|c|c|c|}
\hline UniProt accession number & Protein name & $\begin{array}{l}\text { Total } \% \text { of sequence } \\
\text { coverage }\end{array}$ & $\begin{array}{l}\text { K0 normalized } \\
\text { spectral count }\end{array}$ & $\begin{array}{l}\text { WT normalized } \\
\text { spectral count }\end{array}$ & $\begin{array}{l}\text { Ratio } \\
\text { KO/WT }\end{array}$ \\
\hline \multicolumn{6}{|l|}{ Tubulins } \\
\hline P68369 & Tubulin alpha-1A chain & 57 & $1995( \pm 67)$ & $1939(37)$ & 1 \\
\hline P05213 & Tubulin alpha-1B chain & 57 & $1357( \pm 72)$ & $1358( \pm 61)$ & 1 \\
\hline P68373 & Tubulin alpha-1C chain & 51 & $1356( \pm 73)$ & $1357( \pm 62)$ & 1 \\
\hline Q7TMM9 & Tubulin beta-2A chain & 53 & $1497( \pm 154)$ & $1535( \pm 323)$ & 1 \\
\hline Q9CWF2 & Tubulin beta- $2 B$ chain & 53 & $1517( \pm 154)$ & $1562( \pm 322)$ & 1 \\
\hline P68372 & Tubulin beta- $2 C$ chain & 52 & $1346( \pm 147)$ & $1415( \pm 284)$ & 1 \\
\hline Q9ERD7 & Tubulin beta-3 chain & 60 & $1338( \pm 122)$ & $1398( \pm 253)$ & 1 \\
\hline P68368 & Tubulin alpha-4A chain & 46 & $822( \pm 45)$ & $877( \pm 57)$ & 0.9 \\
\hline Q9D6F9 & Tubulin beta- 4 chain & 55 & $908( \pm 89)$ & $988( \pm 222)$ & 0.9 \\
\hline P99024 & Tubulin beta- 5 chain & 56 & $1708( \pm 192)$ & $1741( \pm 296)$ & 1 \\
\hline Q3UX10 & Tubulin alpha chain-like 3 & 6.7 & $126( \pm 6.2)$ & $138( \pm 13.2)$ & 0.9 \\
\hline P48428 & Tubulin-specific chaperone A & 41 & $4( \pm 2)$ & $6( \pm 1.5)$ & 0.7 \\
\hline Q8K341 & Alpha-tubulin $\mathrm{N}$-acetyltransferase & 27 & $32( \pm 6.2)$ & $19( \pm 5.3)$ & 1.7 \\
\hline Q3UDE2 & Tubulin-tyrosine ligase-like protein 12 & 14 & $2.6( \pm 1.2)$ & $4.7( \pm 2.9)$ & 0.6 \\
\hline Q9D1E6 & Tubulin-folding cofactor B & 18 & $3( \pm 2)$ & $2( \pm 0.9)$ & 1.5 \\
\hline \multicolumn{6}{|l|}{$\begin{array}{l}\text { Microtubule associated } \\
\text { proteins }\end{array}$} \\
\hline 088809 & Doublecortin & 27 & $0.42( \pm 0.72)$ & $30( \pm 7)$ & 0.014 \\
\hline Q91VR7 & Microtubule-associated proteins $1 \mathrm{~A} / 1 \mathrm{~B}$ light chain $3 \mathrm{~A}$ & 12 & $32.6( \pm 0.1)$ & $1.8( \pm 1)$ & 1.7 \\
\hline Q9CQV6 & Microtubule-associated proteins $1 \mathrm{~A} / 1 \mathrm{~B}$ light chain $3 \mathrm{~B}$ & 12 & $2.6( \pm 0.11)$ & $3.4( \pm 0.8)$ & 0.8 \\
\hline P14873 & Microtubule-associated protein 1B & 39 & $782( \pm 251)$ & $941( \pm 216)$ & 0.8 \\
\hline Q8C052 & Microtubule-associated protein 15 & 8.8 & $6.9( \pm 3.9)$ & $4.9( \pm 1.7)$ & 1.4 \\
\hline P20357 & Microtubule-associated protein 2 & 19 & $32( \pm 9.3)$ & $46( \pm 13.2)$ & 0.7 \\
\hline P27546 & Microtubule-associated protein 4 & 24.6 & $15( \pm 17)$ & $18( \pm 12)$ & 0.8 \\
\hline Q7TSJ2 & Microtubule-associated protein 6 & 14 & $13( \pm 0.5)$ & $14( \pm 3.2)$ & 0.9 \\
\hline Q61166 & Microtubule-associated protein RP/EB family member 1 & 37 & $18( \pm 3)$ & $21( \pm 6)$ & 0.9 \\
\hline Q8R001 & Microtubule-associated protein RP/EB family member 2 & 16 & $5( \pm 4)$ & $5( \pm 2)$ & 1 \\
\hline Q6PER3 & Microtubule-associated protein RP/EB family member 3 & 11 & $0.8( \pm 1.4)$ & $2( \pm 0.9)$ & 0.4 \\
\hline P10637 & Microtubule-associated protein tau & 23 & $26( \pm 20)$ & $48( \pm 20)$ & 0.5 \\
\hline Q9QXZO & Microtubule-actin cross-linking factor 1 & 3.7 & $15( \pm 12)$ & $12( \pm 9)$ & 1.3 \\
\hline Q80TV8 & Clasp1 & 4 & $0.9( \pm 0.8)$ & $1( \pm 1.7)$ & 0.9 \\
\hline Q8BRT1 & Clasp2 & 6.8 & $2.5( \pm 4)$ & $1.6( \pm 0.3)$ & 1.6 \\
\hline Q9ZOH8 & Clip2 & 23 & $24( \pm 11)$ & $20( \pm 17)$ & 1.2 \\
\hline P54227 & Stathmin & 45 & $24( \pm 4.9)$ & $40( \pm 13.9)$ & 0.6 \\
\hline
\end{tabular}

square cover glasses the day before axon guidance assay. The Dunn chamber is assembled as described previously (Zicha et al., 1997; Wells and Ridley, 2005; Yam et al., 2009). Time-lapse images were acquired using a $20 \times$ objective (IX81, Olympus America) every 3 min for $2.5 \mathrm{~h}$. Analysis of time-lapse imaging was performed with MetaMorph and ImageJ and calculated as described previously (Yam et al., 2009).

\section{Results}

Mass spectrometry on corpus callosum from Dcx mutant mice demonstrates defects in actin-binding proteins

In addition to defects in neuronal migration, $D c x^{-1 y} ; D c l k 1^{-1-}$ mutants also have significantly thinned or absent axon tracts, including corpus callosum and anterior commissures (Deuel et al., 2006; Koizumi et al., 2006; Kappeler et al., 2007) (Fig. 1A,B). To determine why Dcx family mutant neurons have axonal defects, we used mass spectrometry of corpus callosum isolated by microdissection (Fig. 1C) for an unbiased ascertainment of differences in protein expression between mutant and wild-type axons. Because the $D c x^{-/ y} ; D c l k 1^{-1-}$ mouse has a thin or absent corpus callosum, we conducted our experiments on the $D c x^{-/ y}$ single mutant with an intact axon tract (Fig. 1B). Since Dcx is developmentally regulated, we chose to sample early stages ( $\mathrm{P} 0$ to $\mathrm{P} 2$ ) when it is expressed, with the added advantage that these stages precede the onset of myelination so that the corpus callosum is comprised of a relatively pure proportion of axon tracts.
As proof of principle of our axon screen in mutant mice, we performed this assay on wild-type axon tracts. By cutting coronal sections at 500 microns on fresh brain at postnatal day 2 (P2) we were able to isolate and micro dissect the corpus callosum and anterior commissure (Fig. 1C). We ran Western analysis on the lysates of microdissected corpus callosum and ran axonal and dendritic markers to determine whether our dissection resulted in an enrichment of axons (Fig. 1D). The traditional dendritic marker MAP2 was decreased but not entirely excluded from the developing corpus callosum. In contrast, markers for the Golgi organelle, which is exclusively dendritic, shows expression in cortical lysates but is entirely absent in the axonal lysates of the corpus callosum and anterior commissures. We ran an initial mass spectrometry experiment on the protein from a single wild-type corpus callosum lysate and were able to detect 865 different proteins. Classification of these proteins using the UniProt search functions revealed a large proportion of cytoskeletal proteins - $14 \%$ including proteins associated with actin, microtubules, and intermediate filaments (Fig. 1E). Other proteins detected were associated with mitochondria, the cell membrane, and secretory organelles including vesicles, endosomes, and ER proteins. The greatest proportion of proteins that were detected by mass spectrometry were cytoplasmic $(46 \%$, Fig. $1 E)$. Thus, proteins of interest are easily detectable in microdissected corpus callosum at an early postnatal stage. 
We next compared protein expression in axon tracts from Dcx mutant mice with their wild-type littermate controls. We microdissected the corpus callosum at P2 from three $D c x^{-l y}$ and three wild-type $D c x^{+/ y}$ mice. We compared levels of cytoskeletal proteins by examining the normalized spectral counts in both wild-type and $D c x^{-/ y}$ axons. We chose proteins for primary candidates for validation using several criteria: enough abundance (normalized count $>5$ in either wild-type or mutant condition), reasonable specificity (with $>10 \%$ sequence coverage), and alterations of expression either greater than or equal to a $50 \%$ change in either direction, recognizing that these cutoffs are arbitrary and that subtle variations in expression level are unlikely to appear in our screen.

While tubulin isoforms appear unchanged in our screen (Table 1), some MAPs appear to be differentially affected in the Dcx mutant axons. It is known that Tau 1 microtubule distribution is changed by the absence of Dcx (Tint et al., 2009), and we find that overall Tau is decreased in axons of $D c x^{-/ y}$ mutants (Table 1). Other MAPs, MAP1A/1B and CLASP-2, are changed but miss our criteria for priority validation based on the spectral counts of the proteins.

Thus, the proteomic data do not support wide-spread dysregulation in microtubule composition or associated proteins despite the fact that Dcx is a microtubuleassociated protein. We confirmed these findings by examining microtubules in the $D c x^{-1 y} ; D c l k 1^{-1-}$ neurons. We examined MTs by tubulin- $\alpha$ immunostaining in Dcx/Dclk1 deficient neurons in parallel; we found that MTs look very similar to the wild type (WT) (Fig. 2A). Meanwhile, since $\alpha$-tubulin $\mathrm{N}$-acetyltransferase is increased in Dcx mutant axons (Table 1) and posttranslational effects are important for microtubule functions(Hammond et al., 2008; Creppe et al., 2009), we examined whether these changes in MTs are different in Dcx/Dclk1-deficient neurons versus WT and found no changes in single or double mutant neurons by immunostaining or Western analysis. Immunostaining of double-deficient neurons showed no change in polyglutamylated tubulin as compared to WT neurons (Fig. 2B). In addition, Western analysis of P0 cortical lysates from $D c x^{-/ y}$ showed no statistically significant changes in polyglutamylated, acetylated, or tyrosinated tubulin levels (Fig. 2C) and cortical lysates from the double mutant $D c x^{-l y} ; D c l k 1^{-1-}$ did not show reductions in modified tubulin (Fig. 2D). We also tested the Taul changes shown in the proteomic screen and showed that in WT neurons tau- 1 is bound to MTs in the neuronal cell body as well as in proximal neurites. We found that in Dcx/Dclk1-deficient neurons, tau-1 binding to MTs in the soma is consistent, while tau- 1 distribution in the proximal neurite is decreased (Fig. $2 E, F$ ). Thus, we find that while tau-1 all panels represent $10 \mathrm{~mm}$.
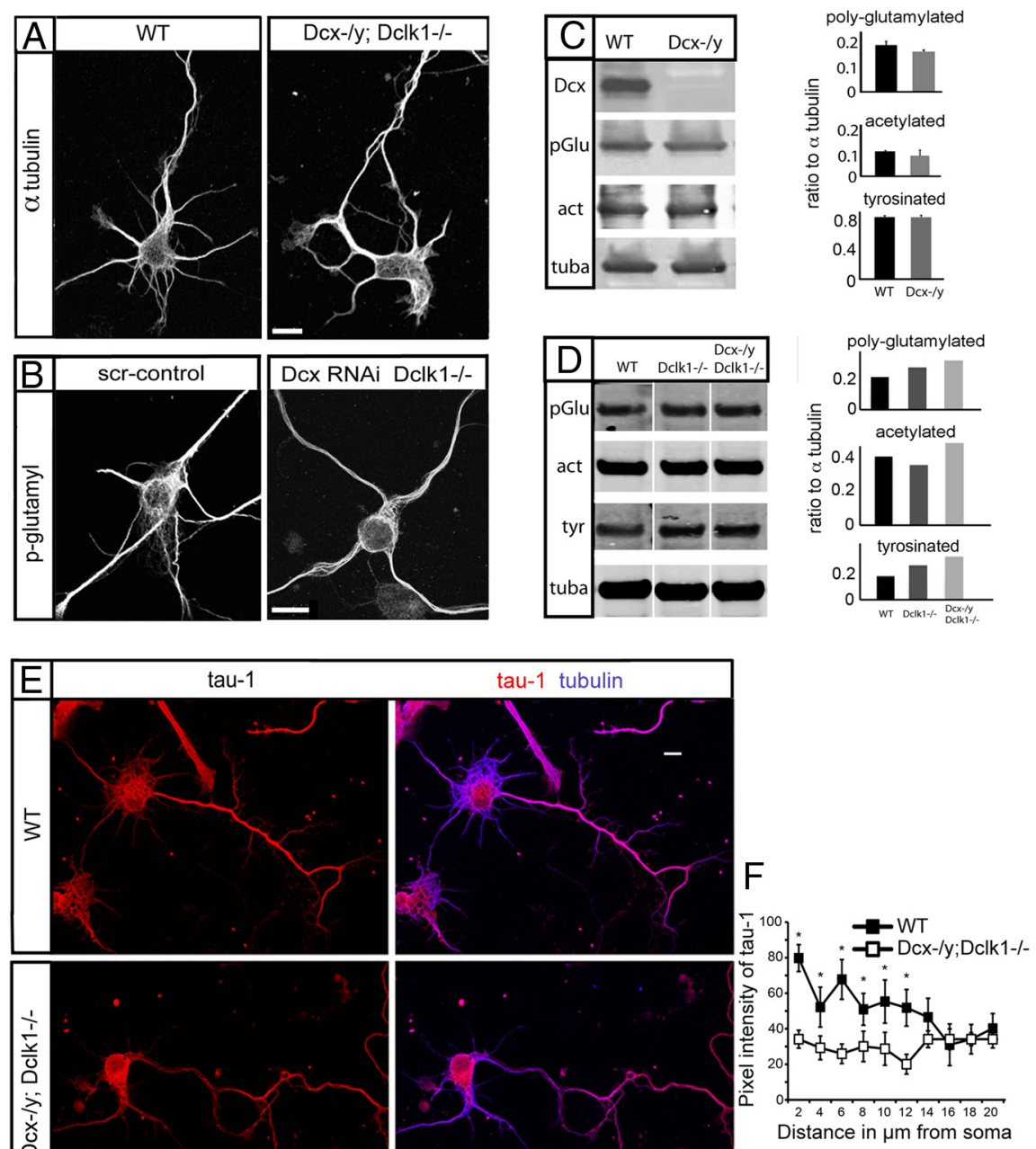

Figure 2. Wild-type and $D c x / D c l k 1$ deficient neurons have few differences in terms of tubulin structure, posttranslational ated tubulin appears to be similar in both control and Dcx/Dclk1-deficient neurons. C, Western analysis in wild-type and $D c x^{-/ y}$ brain lysates for polyglutamylated, acetylated, and tyrosinated tubulin show no significant differences. $\boldsymbol{D}$, Western analysis of mutants of these posttranslational modifications. $\boldsymbol{E}$, Immunostaining of Tau-1 (red) and tubulin (blue) in cultured WT and $D c x^{-1 y}$; cortical neurons. $\boldsymbol{F}$, Quantification of pixel intensity of tau- 1 staining from $\mathrm{E}\left({ }^{*} p<0.05, t\right.$ test). In $D c x^{-/ y} ; D c / k 1$ neurons, tau- 1 binding to MTs in the soma is consistent, while tau- 1 distribution in the proximal neurite is decreased. Scale bars in

distribution is changed in Dcx/Dclk1-deficient neurons, for the most part MAPs and tubulin are not dramatically altered.

In contrast, a larger number of actin-binding proteins are dysregulated in $D c x^{-l y}$ axons, although actin levels are not changed (Table 2). Western blotting and immunostaining for $\beta$-actin also confirm that the levels of actin subunits are not changed in $D c x^{-/ y}$ axons (Fig. 3A, $B$ and Fig. $4 G$ ). Dcx is known to interact with both actin as well as microtubules. Dcx is thought to be a mediator of actin/microtubule cross talk (Tsukada et al., 2005; Coquelle et al., 2006; Bielas et al., 2007; Santra et al., 2009). Our screen shows that the absence of Dcx results in dysregulation of actin-binding proteins, including $\alpha$-actinin- 1 and $\alpha$-actinin- 4 and actin-related protein $2 / 3$ complex subunit 3 (Arp3), as well as profilin (Table 2).

Because a larger proportion of actin-associated proteins are dysregulated, we focused on these for both validation and phenotypic characterization of the doublecortin family mutant neurons. We validated $\alpha$-actinin and Arp proteins by 
Table 2. Differential expression of actin-related proteins

\begin{tabular}{|c|c|c|c|c|c|}
\hline $\begin{array}{l}\text { UniProt accession number } \\
\text { actin- related proteins }\end{array}$ & Protein name & $\begin{array}{l}\text { Total \% of sequence } \\
\text { coverage }\end{array}$ & $\begin{array}{l}\text { K0 normalized } \\
\text { spectral count }\end{array}$ & $\begin{array}{l}\text { WT normalized } \\
\text { spectral count }\end{array}$ & $\begin{array}{l}\text { Ratio } \\
\text { KO/WT }\end{array}$ \\
\hline P60710 & Actin, cytoplasmic 1 & 69 & $759( \pm 189)$ & $631( \pm 59)$ & 1.2 \\
\hline P63260 & Actin, cytoplasmic 2 & 69 & $759( \pm 189)$ & $631( \pm 59)$ & 1.2 \\
\hline Q6R891 & Neurabin-2 & 12 & $1.7( \pm 1.9)$ & $1.2( \pm 1)$ & 1.4 \\
\hline Q9D898 & $\begin{array}{l}\text { Actin-related protein 2/3 complex subunit } 5 \text {-like } \\
\text { protein }\end{array}$ & 30 & $3.9( \pm 1.2)$ & $2.8( \pm 1.3)$ & 1.4 \\
\hline Q9JM76 & Actin-related protein $2 / 3$ complex subunit 3 & 41 & $3.9( \pm 3.8)$ & $7.2( \pm 3)$ & 0.5 \\
\hline P59999 & Actin-related protein $2 / 3$ complex subunit 4 & 13 & $1.3( \pm 1.3)$ & $4.4( \pm 1.4)$ & 0.3 \\
\hline Q810U3 & Neurofascin & 3.7 & $5.16( \pm 2.5)$ & $3.26( \pm 1.6)$ & 1.6 \\
\hline Q9WUM4 & Coronin-1C & 16 & $3.9( \pm 1.2)$ & $2.2( \pm 3)$ & 1.8 \\
\hline Q7TPR4 & Alpha-actinin-1 & 15.5 & $7( \pm 4.2)$ & $13( \pm 1.7)$ & 0.5 \\
\hline P57780 & Alpha-actinin-4 & 30 & $9( \pm 5)$ & $19( \pm 3)$ & 0.5 \\
\hline P26040 & Ezrin & 19 & $28( \pm 14)$ & $27( \pm 3)$ & 1 \\
\hline Q61553 & Fascin & 26 & $36( \pm 7)$ & $37( \pm 12)$ & 1 \\
\hline Q9QUI0 & Transforming protein RhoA & 28 & $10( \pm 3)$ & $13( \pm 2)$ & 0.8 \\
\hline P40124 & Adenylyl cyclase-associated protein 1 & 16 & $20( \pm 7)$ & $15( \pm 3)$ & 1.3 \\
\hline P47757 & F-actin-capping protein subunit beta & 21 & $4.7( \pm 0.6)$ & $2.8( \pm 2.4)$ & 1.7 \\
\hline P47753 & F-actin-capping protein subunit alpha-1 & 27 & $3.5( \pm 2)$ & $3.2( \pm 1.6)$ & 1.1 \\
\hline P47754 & F-actin-capping protein subunit alpha-2 & 35 & $3.9( \pm 1.2)$ & $4.4( \pm 1.4)$ & 0.9 \\
\hline Q9DAW9 & Calponin-3 & 24 & $2( \pm 2.7)$ & $3.4( \pm 0.8)$ & 0.6 \\
\hline P18760 & Cofilin-1 & 46 & $78( \pm 35)$ & $101( \pm 17)$ & 0.8 \\
\hline 089053 & Coronin-1A & 10 & $2( \pm 0.7)$ & $2( \pm 0.9)$ & 1 \\
\hline Q90XS6 & Drebrin & 28 & $65( \pm 21)$ & $59( \pm 16)$ & 1.1 \\
\hline Q62418 & Drebrin-like protein & 7.6 & $3( \pm 2)$ & $2.3( \pm 1.8)$ & 1.3 \\
\hline Q9Z2H5 & Band 4.1-like protein 1 & 8 & $1( \pm 2)$ & $2.4( \pm 0.9)$ & 0.4 \\
\hline Q9WV92 & Band 4.1-like protein 3 & 8 & $9( \pm 3.8)$ & $6.8( \pm 6.7)$ & 1.3 \\
\hline Q8BTM8 & Filamin-A & 13.7 & $13.5( \pm 6)$ & $20( \pm 13)$ & 0.7 \\
\hline P13020 & Gelsolin & 7 & $1.4( \pm 2.4)$ & $1.3( \pm 2.3)$ & 1.1 \\
\hline P63005 & LIS1 & 15.4 & $11( \pm 4)$ & $11( \pm 3.4)$ & 1 \\
\hline P62962 & Profilin-1 & 47 & $24( \pm 7)$ & $16( \pm 1.7)$ & 1.5 \\
\hline Q9JJV2 & Profilin-2 & 40 & $3.9( \pm 2.5)$ & $3.9( \pm 1.8)$ & 1 \\
\hline P60764 & Ras-related $(3$ botulinum toxin substrate 3 & 29 & $4( \pm 1.5)$ & $8.4( \pm 3)$ & 0.5 \\
\hline P60766 & Cell division control protein 42 homolog & 28 & $8( \pm 1)$ & $9( \pm 7)$ & 0.9 \\
\hline Q80ZJ1 & Ras-related protein Rap-2a & 34 & $6( \pm 1.8)$ & $7.4( \pm 2.6)$ & 0.8 \\
\hline P32883 & GTPase KRas & 34 & $3.4( \pm 3.2)$ & $3.7( \pm 0.7)$ & 0.9 \\
\hline Q9QUI0 & Transforming protein RhoA & 28 & $10( \pm 3)$ & $13( \pm 1.6)$ & 0.8 \\
\hline P26039 & Talin-1 & 4 & $9( \pm 6)$ & $7( \pm 2.3)$ & 1.3 \\
\hline Q3THE2 & Myosin regulatory light chain $12 B$ & 53 & $9( \pm 6)$ & $13( \pm 2.5)$ & 0.7 \\
\hline Q60605 & Myosin light polypeptide 6 & 30 & $11( \pm 1)$ & $9( \pm 1)$ & 1.3 \\
\hline Q61879 & Myosin-10 & 38 & $128( \pm 30)$ & $111( \pm 41)$ & 1.2 \\
\hline Q61RU2 & Tropomyosin alpha-4 chain & 18 & $1.7( \pm 1.5)$ & $1.4( \pm 1.5)$ & 1.2 \\
\hline Q8C143 & Myosin light chain 6B & 14 & $3( \pm 2)$ & $2.9( \pm 0.1)$ & 1.2 \\
\hline Q99104 & Myosin-Va & 5 & $8( \pm 2)$ & $4.5( \pm 4.8)$ & 1.8 \\
\hline Q9CQ19 & Myosin regulatory light polypeptide 9 & 34 & $3.4( \pm 3.8)$ & $7.3( \pm 1.4)$ & 0.5 \\
\hline Q9JMH9 & Myosin-XVIIIa & 3 & $1.3( \pm 1.3)$ & $1.9( \pm 1.7)$ & 0.7 \\
\hline
\end{tabular}

both immunocytochemistry and Western analysis. Western analysis of axonal lysates of the corpus callosum prepared in the same way as the mass spectrometry experiments shows a decrease in $\alpha$-actinin- 4 in the $D c x^{-/ y}$ single mutant, while comparison of cortical lysates shows no difference (Fig. $3 A, B)$. Distribution of $\alpha$ actinin- 4 was changed in the Dcx/ Dclk1 mutant neurons with increased immunostaining in the cell body and a decrease in neurites, both axons and dendrites (Fig. 3C). In contrast, we found that $\alpha$-actinin-1 was broadly decreased in $D c x^{-1 y} ; D c l k 1^{-1-}$ mutant neurons over the wildtype neurons by immunostaining (Fig. 3D). Because of the properties of the $\alpha$-actinin- 1 antibody, we were not able to perform Western analysis on axonal and cortical lysates.

Like $\alpha$-actinin-1, Western analysis of Arp3 using lysates from microdissected corpus callosum showed a decrease in the $D c x^{-1 y}$ single mutant (Fig. 4A), in contrast to the cortical lysate in which levels of Arp3 were unchanged (Fig. 4B). We tested Arp4 as well, although it narrowly missed our criteria for validation and found that it was unchanged in both axons and cortical plate lysates (Fig. $4 C, D$ ). We were also unable to show a change in Arp4 by immunocytochemistry (Fig. $4 F$ ); however, we find a decrease in Arp3 in the neurites of $D c x^{-1 y} ; D c l k 1^{-1-}$ double mutant neurons, but not in the cell body (Fig. 4E). Finally, we confirmed by Western analysis that actin subunits were not altered between $D c x^{-/ y}$ mutants and wild-type for all lysates used to test $\alpha$-actinin and Arp (Fig. $3 A, B$ and Fig. $4 A-D$ ). Furthermore, immunostaining shows similar $\beta$-actin levels in $D c x^{-l y}$ mutants versus wild type. Thus, we are able to validate the decrease seen in our screen for three actin-binding proteins by either Western analysis or immunocytochemistry.

\section{F-actin is redistributed in $D c x^{-/ y} ; D c l k 1^{-/-}$mutant neurons}

Because of the selective decrease in these actin-associated proteins in the axons of $D c x^{-1 y}$ despite similar levels of actin sub- 


\section{A: Lysate from corpus callosum}
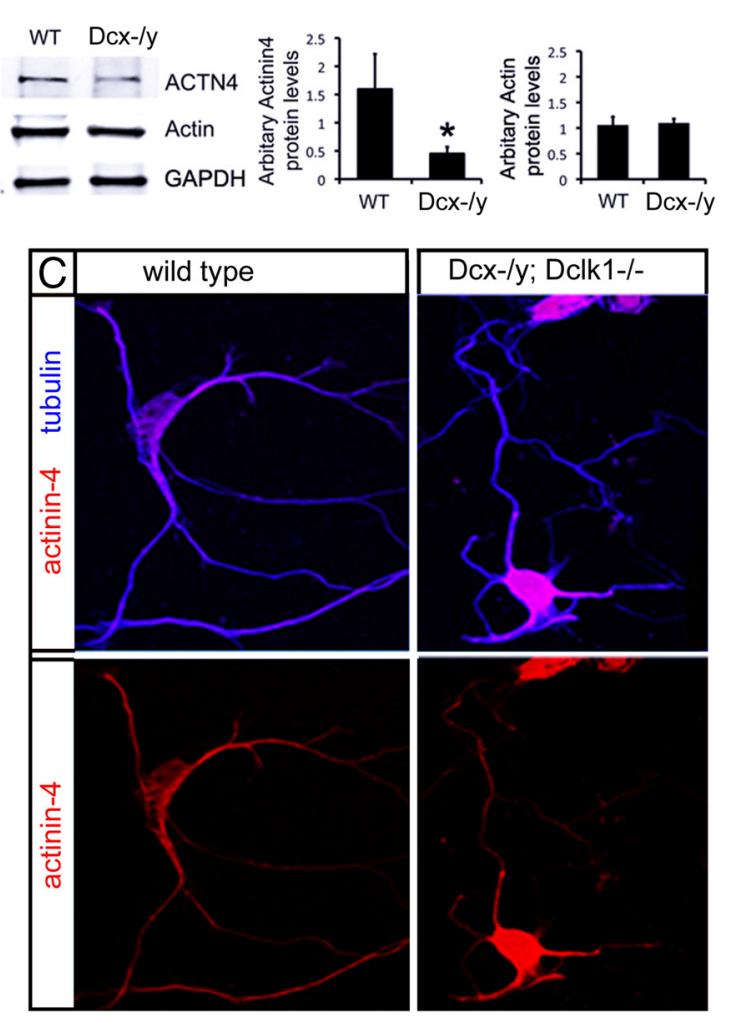

\section{B: Lysate from cortex}
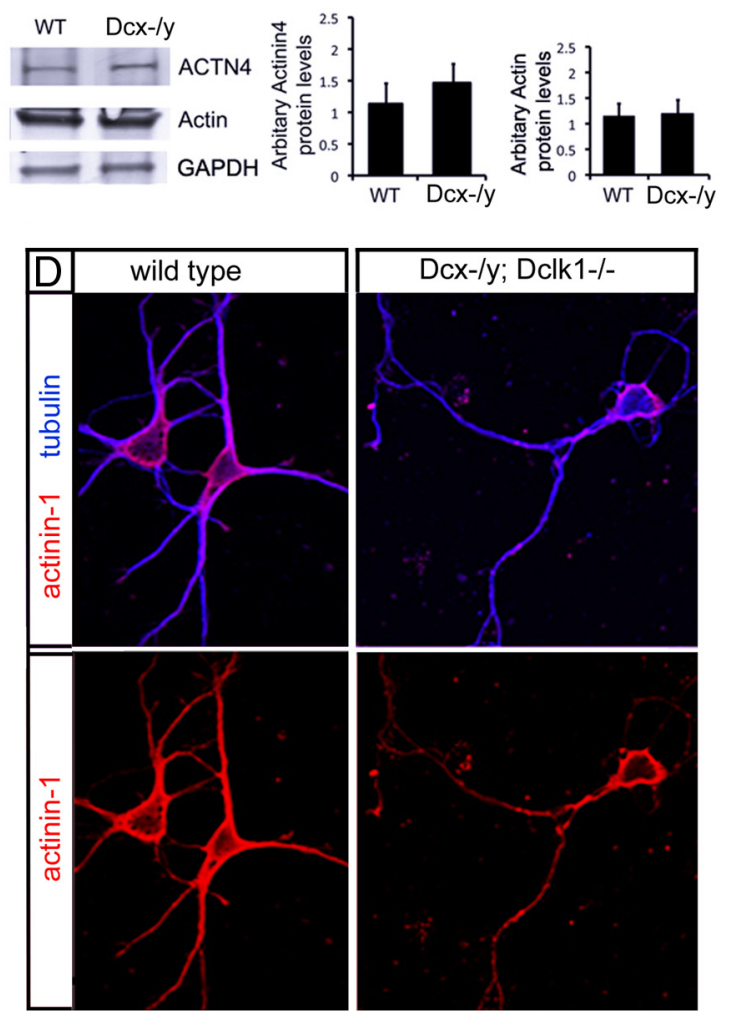

Figure 3. Alpha-actinin-1 and -4 are decreased in axons of Dcx/ Dclk1 deficient neurons. $A$, Western blotting for $\alpha$-actinin-4 using lysates from corpus callosum of WT and Dcx $-1 y$ mutants. Quantification of bands for $\alpha$-actinin- 4 is normalized to bands for actin and calculated based on three Western blotting experiments. An asterisk indicates statistically significant different by $t$ test $\left(^{*} p<0.05\right)$ ( $n=3$ of each genotype). Actin levels are compared to GAPDH levels and shows no difference between WT and Dcx ${ }^{-l y}$. B, By Western analysis the protein levels of $\alpha$-actinin-4 in cortex from $D c x^{-l y}$ are shown to be similar to those in wild type. $\alpha$-Actinin-4 bands are normalized and significance is calculated based on three Western blotting experiments. $C, D, C$ rtical neurons from E 17.5 embryos of WT or $D C x^{-/ y} ; D c l k 1^{-1-}$ neurons were cultured in vitro and immunostained on DIV 5 for $\alpha$-actinin-4 (C) or $\alpha$-actinin-1 (D). The scale bar represents $10 \mu \mathrm{m}$ in both $\boldsymbol{C}$ and $\boldsymbol{D}$.

units, we visualized polymerized actin and found a dramatic redistribution of $\mathrm{F}$-actin by phalloidin staining in $D c x^{-1 y}$; Dclk $1^{-/-}$neurons (Fig. 5). At 5 days in vitro (DIV 5) in both growing axons and dendrites, actin patches form at irregular intervals along neurites, becoming large protrusions containing actin structures with filopodia and lamellipodia (Fig. 5A, arrows) (Spillane et al., 2011; Hu et al., 2012). These form sporadically along both axons and dendrites, as well as around growth cones at the distal tips (Fig. 5A, arrows). We see an increase in F-actin around the cell body of both $D c x^{-l y}$ and the $D c x^{-1 y} ; D c l k 1^{-1-}$ neuron. In the most severe examples, normally discrete actin patches that protrude from the cell body and neurites are fused throughout the whole of the soma ( Fig. $5 B, C$ ). Furthermore, we observe a corresponding decrease in actin protrusions in more distal regions of both axons and dendrites as shown with MAP2 immunostaining (Fig. $5 B, C$ ). We quantified the actin distribution in these neurons by measuring the distance of each actin protrusion (Fig. $5 A$, arrows) from the cell body as demonstrated in Figure $5 A$. We found the numbers of actin protrusions were consistent between wild-type and the single mutant neuron and slightly decreased, but not significantly in the double mutant neurons (Fig. 5D, top). However, the mean distance of actin protrusions from the cell body is significantly reduced in both single Dcx and Dcx/Dclk1 double mutant neurons (Fig. 5D, bottom). We categorized the distances for all of the actin protrusions measured in $5 \mu \mathrm{m}$ bins from 0 to $200 \mu \mathrm{m}$, and then determined the percentages of total in each bin to see the distribution and find that in both single and double mutants measurements clustered much more around the cell body (Fig. 5E-G). The decrease in F-actin in distal regions appears to be most extreme in growth cones (Fig. $5 \mathrm{H}$ ), both dendritic and axonal, where it is almost completely absent in the double mutant. Even at later ages (DIV 7 ), when the phenotype is less severe, there is a decrease in numbers of filopodia (Fig. 5I) and the area of lamellipodia in growth cones (Fig. 5J). Thus, the axon defect may be the result of the dysregulation of actin in the $D c x^{-l y} ; D c l k 1^{-l-}$ neurons, especially at growth cones of mutant neurons.

Because the surprising severity of the actin phenotype in the $D c x^{-l y} ; D c l k 1^{-l-}$ neurons, we conducted a mutational analysis of Dcx to determine the effect on neuronal actin distribution. Our goal was to determine a mechanism through which Dcx regulates actin by selectively disrupting specific functional domains of the Dcx protein. We started by comparing the ability of full-length HA-tagged Dcx to the truncated Dcx to rescue the actin distribution defect in mutant neurons. We transfected both the fulllength and the truncated Dcx into $D c x^{-l y} ; D c l k 1^{-/-}$neurons and found that the truncated $\mathrm{N}$ terminal (1-270 amino acids; Fig. $6 \mathrm{~A}$ ) Dcx construct failed to rescue the actin phenotype in contrast to the full-length Dcx protein, demonstrating that the short C-terminal end missing from our truncation construct is critical for Dcx regulation of actin structure (Fig. 6B-E).

Within the short C-terminal region of Dcx there are several sites of interaction with other proteins including the S297, which is a phosphorylation site regulated by the Dcx interaction with spinophilin (Bielas et al., 2007). The unphosphorylatable mutant Dcx S297A significantly increases F-actin distribution in the pe- 

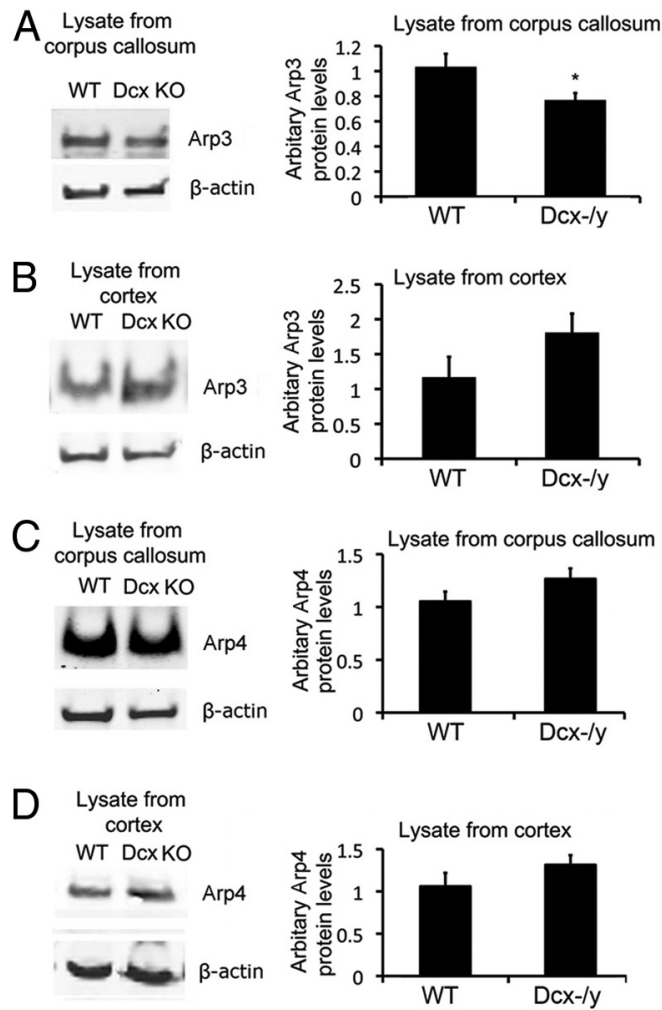
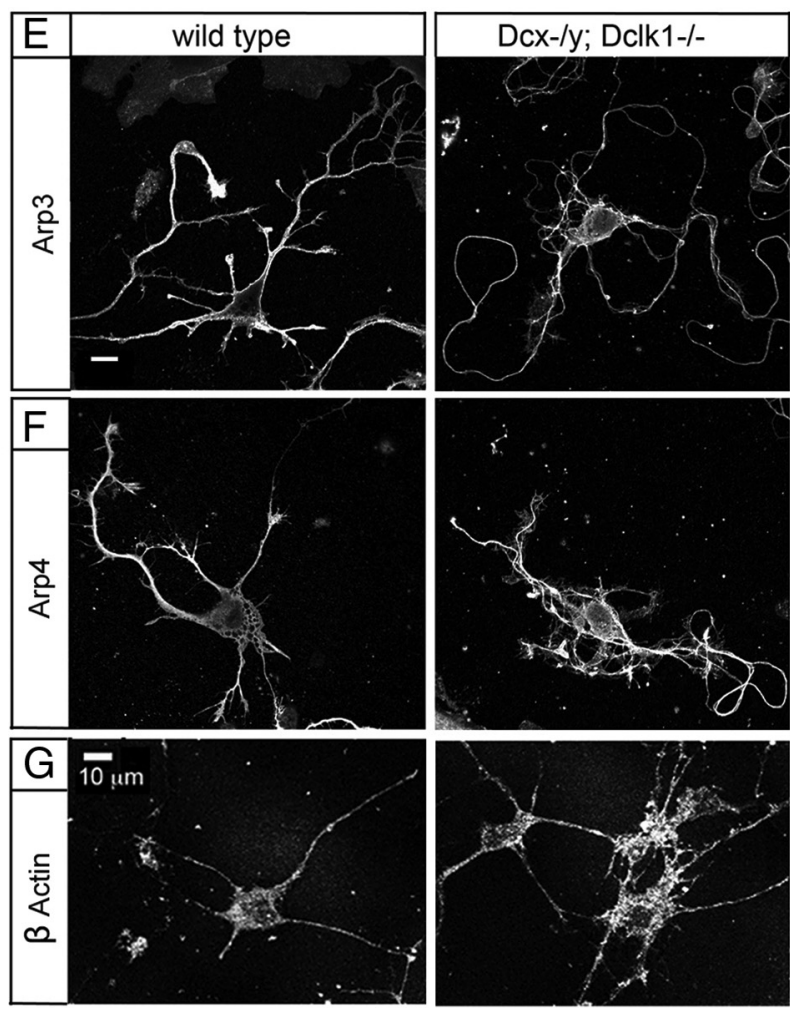

Figure 4. Arp3 is significantly decreased in axons of $D c x$ family mutants as compared to wild-type. $\boldsymbol{A}, \boldsymbol{B}$, Western blotting for Arp3 using proteins from CC $(\boldsymbol{A})$ or cortical plate ( $\boldsymbol{B})$ in WT and Dcx knockout (KO). For quantification of Arp3, bands are normalized to actin and significance is determined based on three Western blotting experiments. An asterisk denotes a significant difference by the $t$ test $\left({ }^{*} p<0.05\right)$. C, D, Western blot analysis of Arp4 using lysate from either corpus callosum or cortical plate show no difference between mutant and wild type. Bands are normalized and $n=$ 3. $\boldsymbol{E}-\mathbf{G}$, Cortical neurons from E17.5 embryos of WT or Dcx/Dclk1 knock out were cultured in vitro and immunostained on DIV 5 for Arp3 (E), Arp4 (F), or $\beta$-actin (G). The scale bar represents $10 \mu \mathrm{m}$ in all panels.

riphery beyond that of the WT Dcx, whereas the phosphomimetic mutant S297D does not change the mean distance of actin distribution in comparison to WT Dcx (Fig. 6F), but appears to cluster actin features near the cell body on the distribution plot (Fig. 6I ). In contrast, the Dcx S47R mutant, which sequesters Dcx in the cell body (Schaar et al., 2004), also results in redistribution of actin away from the neurites toward the cell body as well (Fig. $6 J)$. In addition, point mutations in the region of the $\mu 1$ subunit of AP-1 binding to Dcx (Friocourt et al., 2001) abrogates the association of AP-1 to Dcx (data not shown) and also alters the distribution of actin features without changing the mean distance (Fig. $6 F, K$ ). In the AP-1 binding mutant of Dcx we see no actin features $>80 \mu \mathrm{m}$ from the cell body, in contrast to the WT rescue. Thus, point mutations disrupting protein interactions in the $\mathrm{C}$ terminus of Dcx alter actin distribution.

\section{Dcx interacts with spinophilin but not with Arp3 and $\alpha$-actinin-4}

The next question we asked is how Dcx/Dclk1 actually affects the formation and spatial distribution of filamentous actin protrusions. Immunostaining of Dcx and F-actin in cultured cortical neurons demonstrates that Dcx colocalizes with actin filaments mostly at the distal regions of neurites, where more Dcx proteins are also associated with MTs (Fig. $7 A, B$ ). Therefore, it is possible that Dcx affects actin nucleation or bundling at locations in growth cone through interactions with actin-binding proteins.

We tested whether Dcx interacts with actin-binding proteins directly by coimmunoprecipitation. Our candidates included the validated proteins from our screen, Arp3, $\alpha$-actinin-1, and $\alpha$-actinin-4. In addition, previous studies have shown that the
F-actin bundling protein spinophilin directly interacts with Dcx. To find out whether Dcx interacts with these actin-binding proteins, we cotransfected HEK293 cells with constructs expressing HA-Dcx and GFP-Arp3; GFP- $\alpha$-actinin-1 (Edlund et al., 2001) or spinophilin-GFP (Bloom et al., 2008). Results from immunoprecipitation and Western blotting indicate that Dcx interacts with spinophilin, but not with Arp3 or $\alpha$-actinin-1 (Fig. 7C-E). Similar results are obtained using lysates from mouse brain of WT and $D c x^{-l y}$ (Fig. $7 F-H$ ). These demonstrate the absence of Dcx interactions with endogenous proteins $\alpha$-actinin-4 and Arp3, as well as an in vivo interaction with spinophilin. Because Dcx interactions with spinophilin crosslink the actin and microtubule cytoskeletons, absence of Dcx family proteins may result in defects in dynamic regulation of the cytoskeleton, such as axon guidance.

$D c x^{-/ y} ; D c l k 1^{-/-}$deficient neurons have axon guidance defect We wanted to demonstrate the functional consequence of Dcx/ Dclk1 deficiency and to determine whether defects were consistent with actin dysregulation in these neurons. In both patients with lissencephaly and in Dcx single and $D c x^{-1 y} ; D c l k 1^{-1-}$ double-mutant mice, agenesis of the corpus callosum with Probst-like bundles have been observed. However, immunostaining shows hyperintense abnormal subcortical Tau-1 axonal bundles in the intermediate zone underlying the lateral cortex, indicating an axonal problem more substantial than a defect found just at the midline crossing (Fig. 8A). To characterize the axonal defect, we investigated Dcx effects on guidance versus elongation using an in vitro axon guidance assay performed in a Dunn chamber (Zicha et al., 1997; Wells and Ridley, 2005; Yam et 

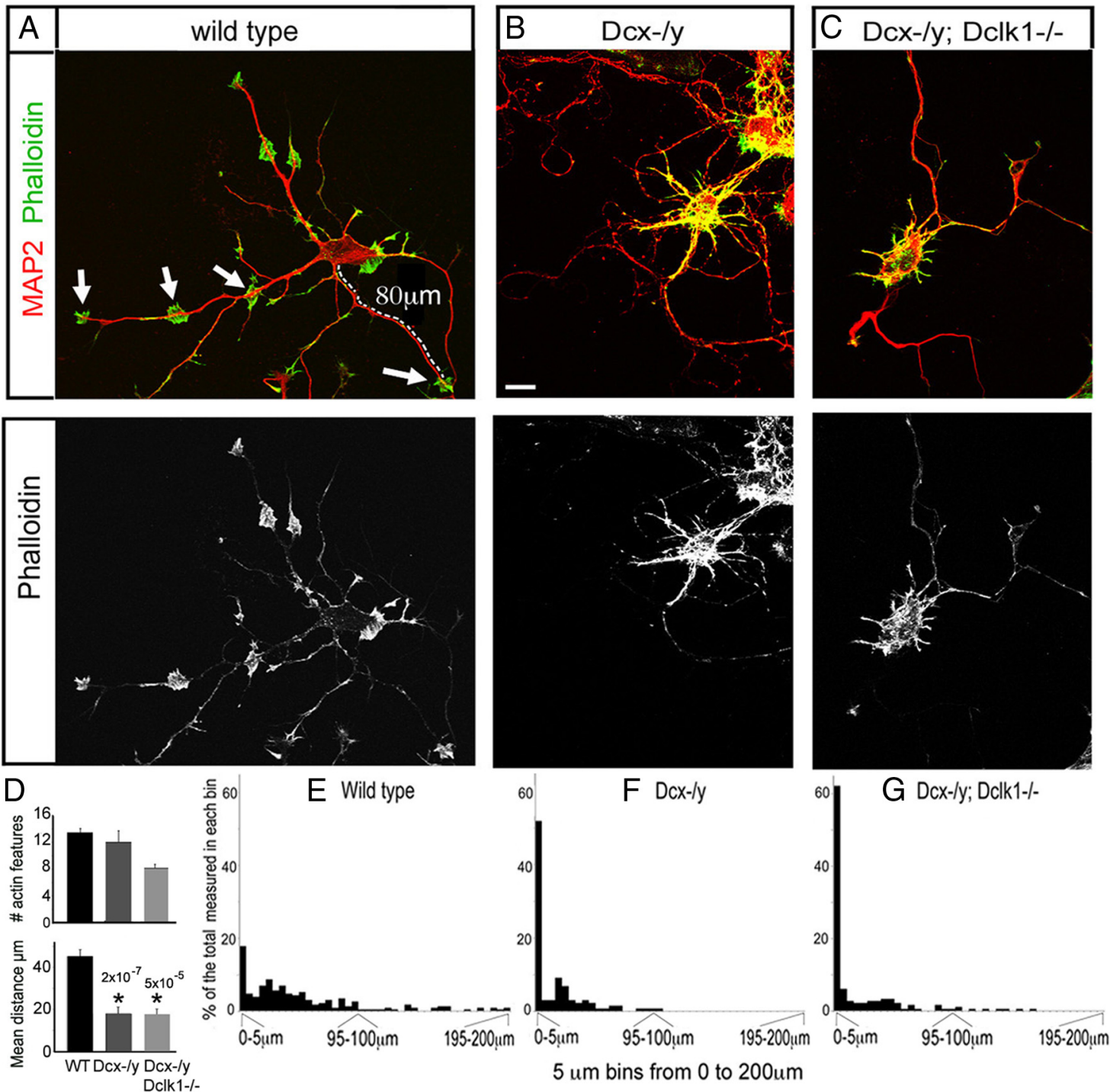

Dclk1-I-
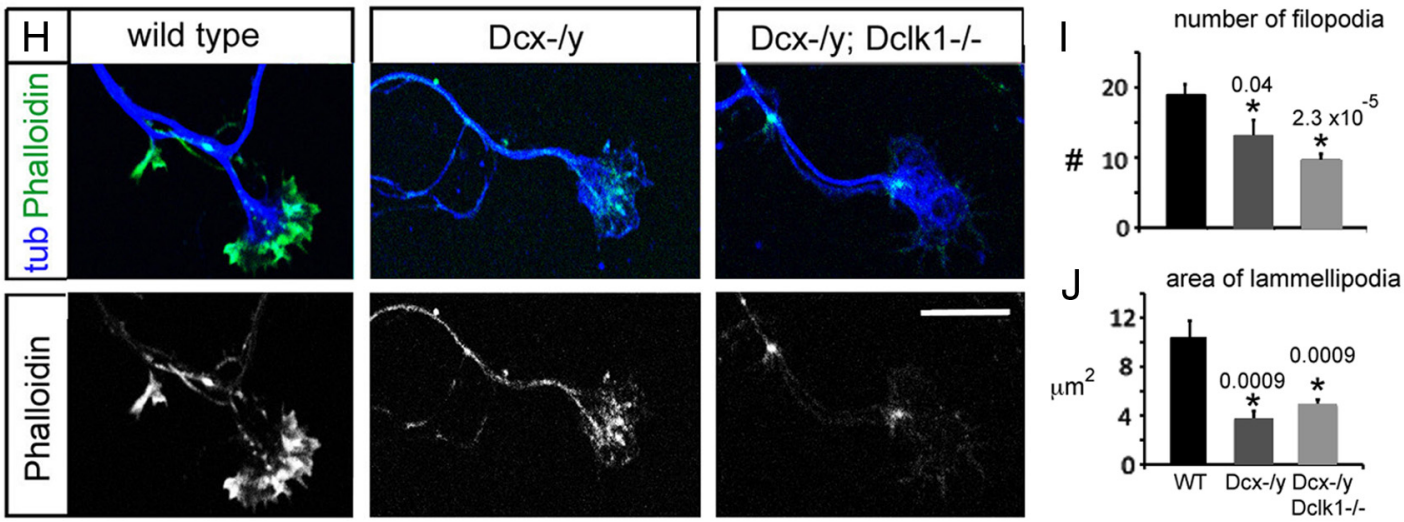

Figure 5. The distribution of F-actin is abnormal in the $D c x / D c l k 1$ deficient neurons compared to wild type. $A, F$-actin is stained with phalloidin in cultured cortical neurons from wild-type, $B, C$, $D C X^{-1 y}(B)$ or $D C x^{-1 y} ; D c l k 1^{-1-}(C)$ mouse brains. Arrows indicate F-actin protrusions along the shaft of the neurites and distal tips. The dotted line shows how the distance of the $F$-actin protrusion to the cell body is determined. The scale bar represents $10 \mu \mathrm{m}$. D, The graph on the top is the measurement of the number of actin protrusions per neuron from each different genotype (black: WT; dark gray: $D c x^{-1 y}$; light gray: $\left.D x^{-/ y}, D c l k{ }^{-l-}\right)$. The graph at the bottom demonstrates the mean distances measured of the $F$-actin protrusions from the cell body in each different genotype. One of five representative experiments is shown. In this experiment, $>10$ neurons are analyzed for each genotype, and $>150$ measurements are made per genotype. Neurons are analyzed at DIV 5 . Error bars are SEM and $p$ values from $t$ test are shown. $\boldsymbol{E}-\boldsymbol{G}$, To show a visual representation of the distribution of actin features, the distance of each actin protrusion from the edge of cell body is measured in wild-type, $D c x^{-l y}$, and $D c x^{-l y} ; D c l k 1^{-l-}$ neurons. The measurements are binned in $5 \mu \mathrm{m}$ categories, and the percentage of the total number measured is graphed for each bin. In mutants $D C x^{-1 y}$ and $D C x^{-1 y} ; D c l k 1^{-1-}$ there is a dramatic increase in the bin $(0-5 \mu \mathrm{m})$ that is closest to the cell body. $\boldsymbol{H}$, F-actin staining by phalloidin is shown in growth cones at DIV5. Scale bars represent $10 \mu \mathrm{m} . I, J$, Numbers of filopodia $(I)$ and the area of lamellipodia $(J)$ are measured in growth cones of wild-type (black), $D c x^{-l y}$ (dark gray), and $D c x^{-1 y} ; D c l k 1^{-I-}$ (light gray) dissociated neurons at DIV 7. Error bars are SEM and $p$ values from $t$ test are shown. 
A

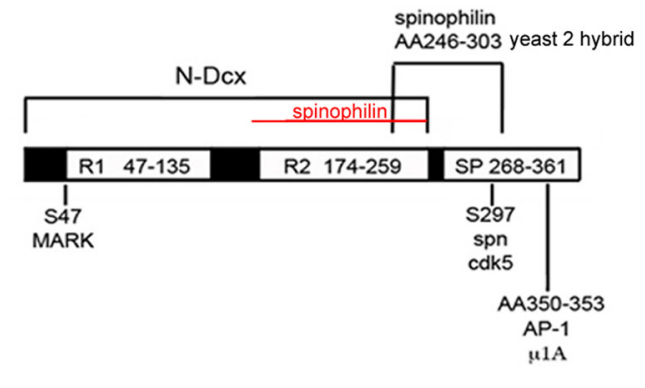

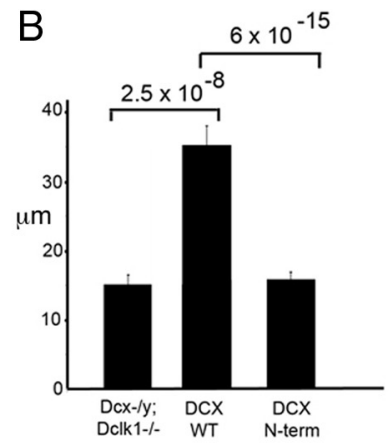
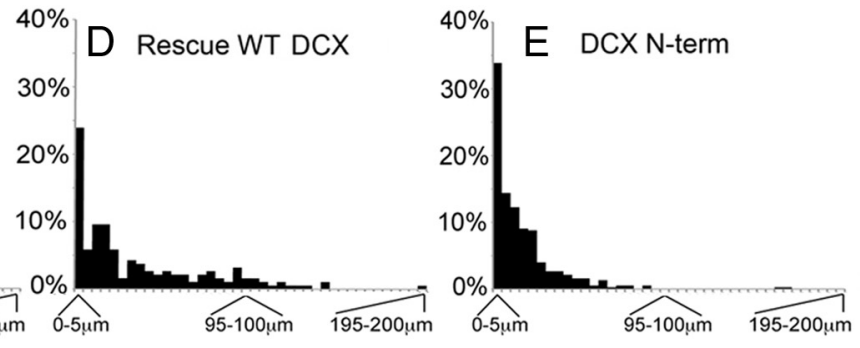

$5 \mu \mathrm{m}$ bins from 0 to $200 \mu \mathrm{m}$
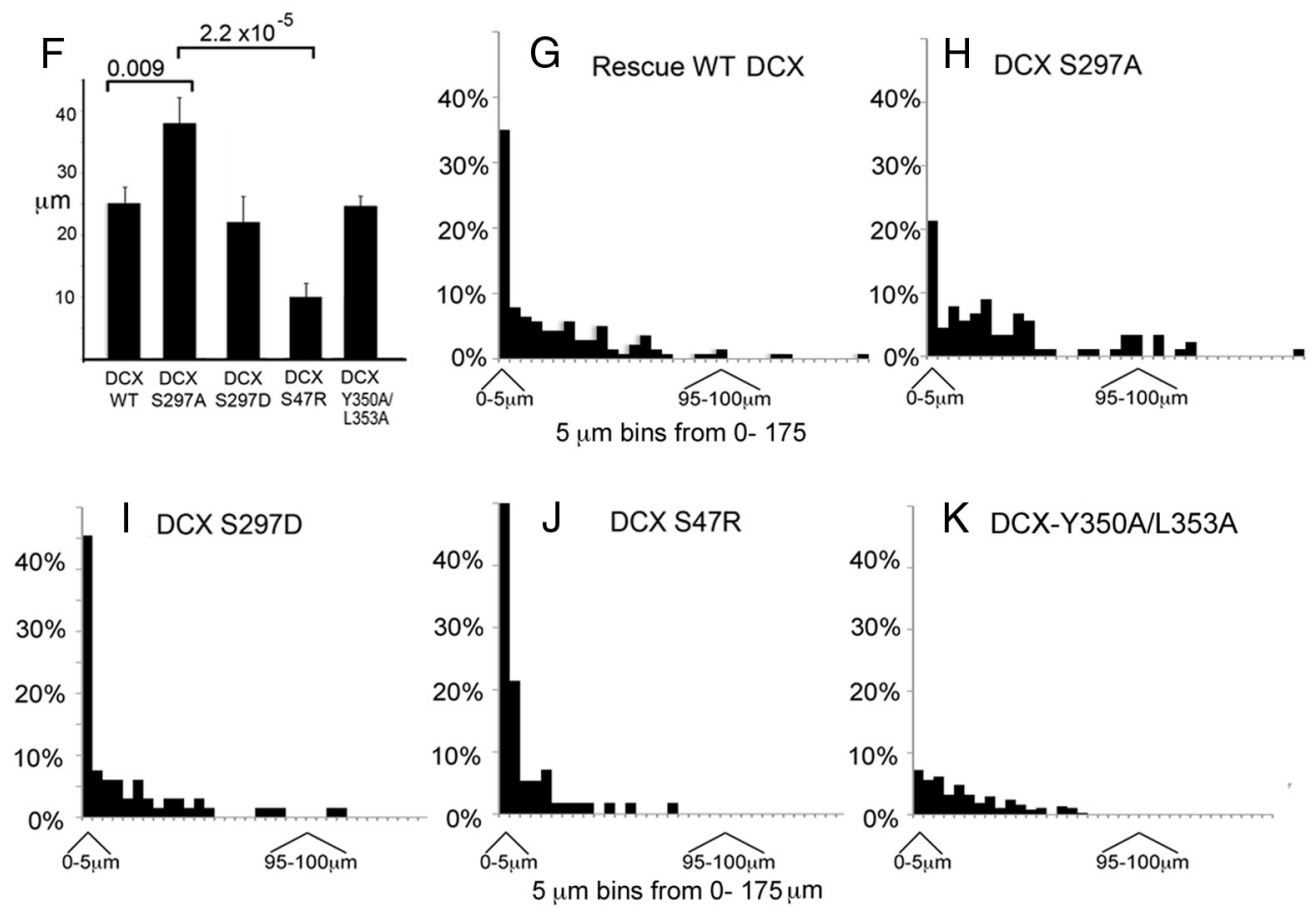

Figure 6. The C-terminal region of Dcx regulates actin structure. $A$, Schematic of Dcx domains and phosphorylation sites. $B$, The mean distance of F-actin protrusions from the edge of cell bodies in cultured $D c x^{-1 y} ; D c k 1^{-I-}$ cortical neurons transfected with/without $D c x$ constructs are compared. Error bars are SEM and $p$ values from $t$ test are shown. Overexpression of the $D c x \mathrm{~N}$ terminus construct in $D c x^{-l y} ; D c k 1^{-1-}$ fails to rescue actin phenotype compared to full-length $D c x$. C-E, Distribution of F-actin in cultured $D c x^{-l y}$; Dclk ${ }^{-/-}$cortical neurons without transfection $(\boldsymbol{C})$ or transfected with wild-type full-length $D c x(W T D c x)(D)$ or $D c x N$-term (1-267 N-terminal amino acids) constructs. $F$, The mean distances of F-actin protrusions in $D c x^{-1 y} ; D c k 1^{-/-}$neurons rescued by Dcx bearing different point mutations are compared to WT Dcx. Error bars are SEM and $p$ values from $t$ test are shown. $\mathbf{G}-\boldsymbol{K}$, Distribution off-actin protrusions in cultured $D c x^{-/ y} ; D C l k 1^{-/-}$cortical neurons rescued with WT Dcx- and Dcx-bearing point mutations is shown.

al., 2009), which can be used to set up a molecular gradient. We tested responsiveness to netrin-1, a chemoattractant known to be important for formation of the corpus callosum. Neurons positioned in the netrin gradient bridge region were imaged live (Fig. $8 \mathrm{~B}$ ), and axon turning was determined by measuring the initial and final positions of the distal $10 \mu \mathrm{m}$ of the axon. A positive angle of turning means the trajectory of the axon turns up the gradient, while negative means that growth cones turn down the gradient. Compared to cells in control conditions without a netrin-1 gradient, the growth of axon from wild-type neuron is significantly deviated from the original direction up the netrin gradient $(p=0.16$, Fig. $8 E, F)$. In contrast, growth cones of $D c x^{-l y} ; D c l k 1^{-/-}$knockout neurons do not significantly change direction in the netrin-1 gradient, as the mean angle turned is not significantly different from that of wild-type neurons in control gradient $(p=0.55$; Fig. $8 E, F)$. We also measured net elongation during this assay. Although axons from $D c x^{-l y} ; D c l k 1^{-/-}$knockout neurons are not responsive to the netrin-1, the net growth of 
axons are similar to those of wild type (Fig. 8D). The selective guidance deficiency with preserved elongation is consistent with a defect in actin regulation. Furthermore, we checked mutant neurons for deficiencies in the netrin receptors DCC and UNC5A/B as well as in the downstream signaling molecules focal adhesion kinase and src family kinases (Liu et al., 2004) and protein kinase A (Ming et al., 1997). These were present at equivalent intensities (data not shown), thus eliminating a decrease in netrin receptors and downstream signaling molecules as reasons for the guidance defect.

\section{Discussion}

Using an unbiased assay to determine the cause of the axonal defect in Dcx mutants, we find a decrease in actin-binding proteins in the mutant axons that is correlated with a decrease in polymerized F-actin in distal regions of axons, including growth cones. We find that the $\mathrm{C}$ terminal S/P rich region of $\mathrm{Dcx}$ is critical for the regulation of $\mathrm{F}$-actin distribution. Furthermore, F-actin features are associated with highest levels of Dcx-MT binding in neurites. Coimmunoprecipitation studies show that Dcx directly associates with spinophilin, but not with the other actin-binding proteins we identified from mass spectrometry. Functionally, the defect in $D c x^{-1 y} ; D c l k 1^{-1-}$ axons is consistent with severe actin dysregulation with selectively impaired axon guidance and preserved axonal elongation. Thus, Dcx has significant regulatory effects on actin structure, which is likely to be the basis for the guidance defect in growth cones and the agenesis of the corpus callosum and other axon tracts in vivo.

\section{How does Dcx regulate actin?}

It was surprising to us that our screen identified multiple actin-binding proteins, since the purified Dcx protein has no actin nucleation or bundling affects. However, a decrease in actin-binding proteins Arp3 and $\alpha$-actinin- 1 and -4 is observed in distal neurites. It is likely that the general decrease in actin-binding proteins stems from the decreased filamentous actin in these regions. Less F-actin will result in diminished incorporation of actin-binding proteins. However, a lack of one key actin polymerizing or bundling protein in distal regions of neurites can lead to the decrease in F-actin structures. Because of our recent work with Dcx and molecular motors, we initially thought that a transport defect in actin-binding proteins might be the root cause. However, no delay was found in fluorescence recovery after photobleaching of $\alpha$-actinin-4-GFP and Arp 3-GFP in distal neurites in $D c x^{-l y} ; D c l k 1^{-1-}$ compared with wild type (data not shown). Therefore, the actin dysregulation is not likely due to impaired motor function. Alternatively, an actinbinding protein may interact directly with microtubule-associated
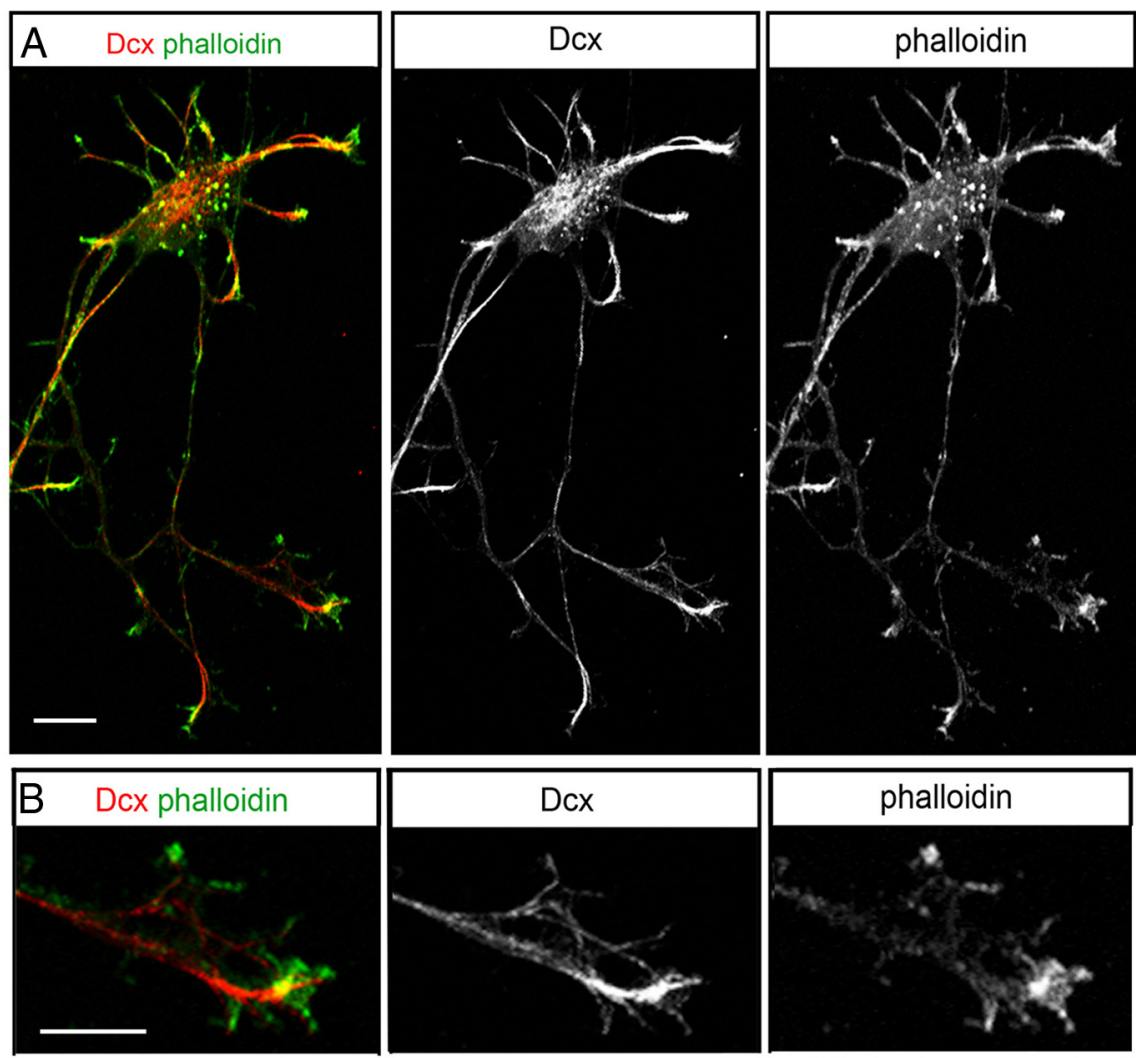

C

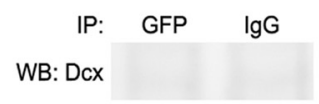

$\mathrm{F}$ IP: Dcx
WB: Arp3

\section{Cell lysate}

Figure 7. Dex interacts with spinophilin but not with Arp3 and $\alpha$-actinin-4. A, Staining of Dcx and actin filaments in cultured cortical neurons from E17.5 WT mouse brain. $\boldsymbol{B}$, High-power view shows the colocalization of Dcx and F-actin at the growth cone. Scale bars in both $\boldsymbol{A}$ and $\boldsymbol{B}$ represent $10 \mu \mathrm{m}$. $\boldsymbol{C}-\boldsymbol{E}$, Hek293 cells are transfected with constructs expressing HA-Dcx and GFP-Arp3 and $\boldsymbol{D}$ ) or HA (E) and Western blot (WB) analysis was performed accordingly. $\boldsymbol{F}$ - $\boldsymbol{H}$, Immunoprecipitation (IP) using brain lysates from WT or Dcx KO mouse for endogenous Dcx and actin-binding proteins $\operatorname{Arp3}(\boldsymbol{F}), \alpha$-actinin-4 (G), and spinophilin $(\boldsymbol{H})$ is shown.
Dcx, as Dcx in axons and dendrites does appear to be localized to regions of actin protrusions. And while $\alpha$-actinin and Arp3 do not interact with Dcx, spinophilin is known to complex with Dcx. Spinophilin is an actin-bundling protein interacting directly with Dcx and is, thus, a good candidate for mediating the actin effects seen in the $D c x^{-l y} ; D c l k 1^{-1-}$ mutants.

While Dcx alone has minimal effects on actin, previous in vitro studies have shown that Dcx interacts with spinophilin, which stimulates F-actin formation and bundles and cross-links actin with microtubules (Tsukada et al., 2003; Tsukada et al., 2005; Bielas et al., 2007; Santra et al., 2009). In our hands, the Dcx/ spinophilin interaction does not appear to change spinophilin localization within the neuron, as $D c x^{-l y} ; D c l k 1^{-l-}$ still demonstrate spinophilin localization indistinguishable from WT. 

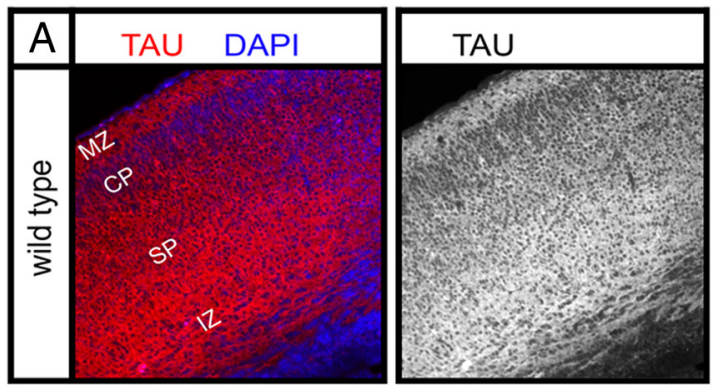

B Dunn chamber
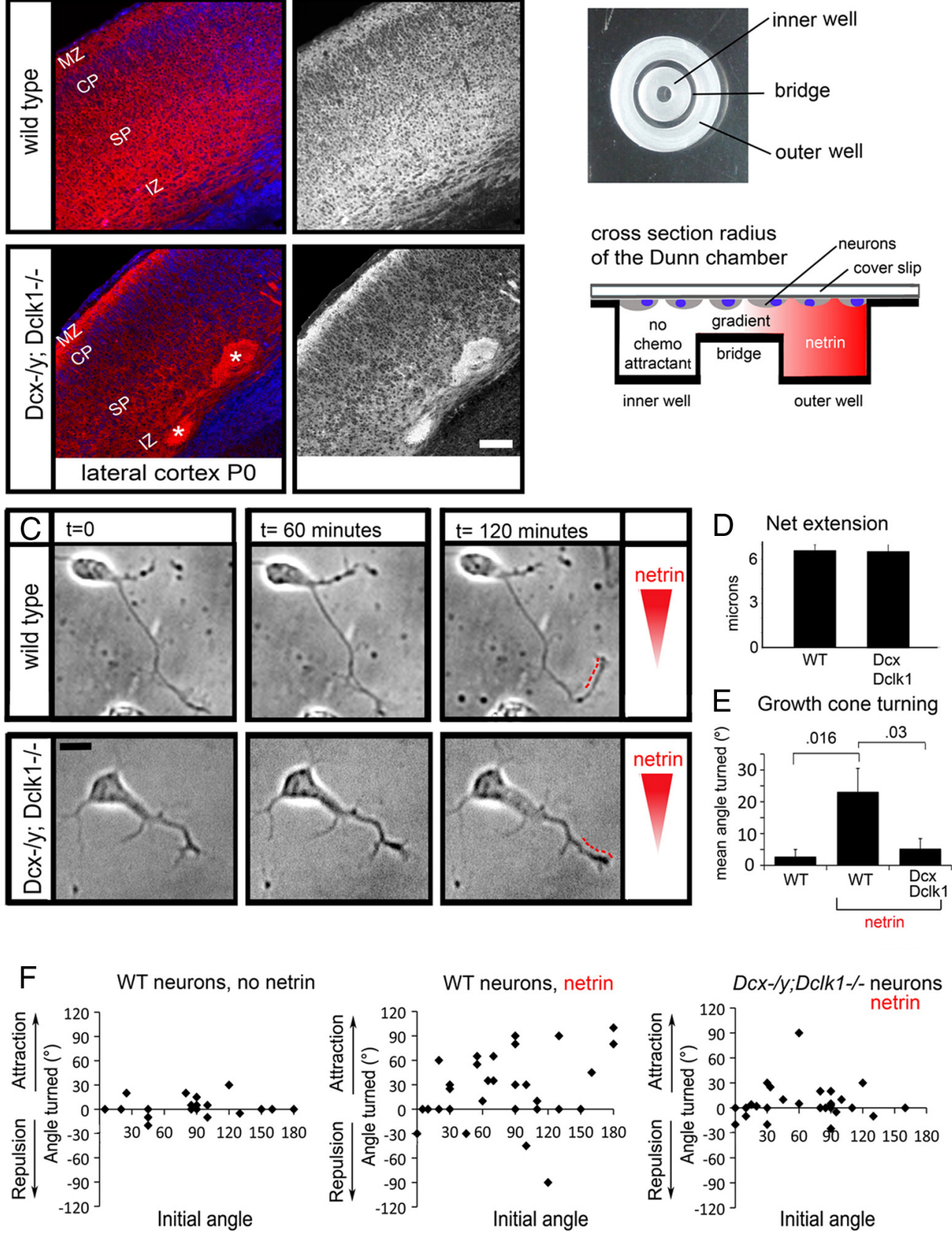

Figure 8. Axonal growth cones from $D C x^{-1 y} ; D c k 1^{-1-}$ cortical neurons are unresponsive in a netrin gradient. $A$, In vivo staining of lateral cortex at postnatal day $0(\mathrm{PO})$ with tau-1 antisera to visualize axons (red). Sections are also costained with the nuclear stain DAPI (blue). Scale bar, $100 \mu \mathrm{m}$. MZ, Marginal zone; CP, cortical plate; SP, subplate; IZ, intermediate zone. Asterisks indicate abnormal axon bundles. $\boldsymbol{B}$, Top view of a Dunn chamber and schematic of Dunn chamber assay is shown. C, A representative cortical neuron of Dcx/Dclk1 knockout does not turn toward increased concentration of netrin $(250 \mathrm{ng} / \mathrm{ml})$ compared to a wild-type cell. Red dotted lines denote the change in elongation over the course of the imaging. Scale bar, $10 \mu \mathrm{m}$. $\boldsymbol{D}$, Quantification of the mean net extension of axons in the presences of the netrin gradient over $2 \mathrm{~h}$. No significant difference is found between wild-type and Dcx/Dclk 1 knockout ( $t$ test). $E$, Quantification and comparison of the mean angle turned for axons from wild-type neurons (in control or netrin gradient) and Dcx/Dclk1 knockout neurons (in netrin gradient). The $p$ values from the $t$ test are calculated ( $n>30)$. $F, S c a t t e r$ plots show the final angle at the end of the assay plotted against the initial angle of the growth cone.

Rather, it appears that Dcx in conjunction with spinophilin enhances actin polymerization and bundling over spinophilin alone (Bielas et al., 2007). Thus, Dcx may regulate or even activate spinophilin-mediated actin effects.

Mapping of the Dcx/spinophilin interaction has produced some conflicting results. Previously, the yeast-two hybrid system maps the interaction to about 10 amino acids in the terminal portion of the second MT binding domain (R2) and 40 amino acids of the small S/P region of Dcx (Tsukada et al., 2003). In contrast, using purified proteins shows that Dcx interacts with spinophilin through the R2 domain exclusively and that the S/P region is regulatory (Bielas et al., 2007). Nevertheless, the S/P region appears to play a role, and our data highlights its importance, since the N-Dcx truncation mutant, missing the S/P domain, fails to rescue the Dcx-actin phenotype. Furthermore, point mutations in the $\mathrm{S} / \mathrm{P}$ region alter the distribution of actin. In particular mutations in the serine residue, which is regulated by spinophilin-mediated dephosphorylation, alters the actin dis- 
tribution. The previous study by Bielas et al. has shown that spinophilin facilitates dephosphorylation of Dcx at S297 (Bielas et al., 2007), which activates Dcx association with the microtubule. Therefore, it is possible that Dcx and spinophilin mediate a complex dynamic interplay between the actin and microtubule cytoskeletons. Taken together, these data suggest a model in which Dcx stimulates actin polymerization and bundling by interacting with spinophilin. Then, spinophilin and protein phosphatase 1 mediate a dephosphorylation of Dcx, causing it to bind to the MT.

Alternatively, Dcx binding on microtubules may regulate actin through a concentration effect. We show that actin formations occur in regions with high levels of Dcx/MT binding that typically occur in distal neurites, increasing to peak levels in growth cones. Thus, these high levels of Dcx/MT binding might alter the distribution of F-actin within neurons by stimulating the formation of polymerization of actin. The threshold effect of Dcx concentration may be due to the fact that at high concentrations Dcx binds MTs cooperatively (Bechstedt and Brouhard, 2012), in contrast to low concentrations of Dcx on MTs. High concentration, cooperative binding of Dcx on MTs requires both R1 and R2 domains of Dcx. Spinophilin binding to Dcx is inhibited by the R1 domain of Dcx (Bielas et al., 2007) so that the incorporation of both domains in the cooperative Dcx/MT complex may regulate the spinophilin Dcx/interaction. Cooperative binding may release the inhibition of the spinophilin interaction domain of Dcx, thus, allowing the binding of spinophilin to areas of saturated Dcx-MT binding.

\section{What is the significance of Dcx regulation of the actin phenotype?}

While our proteomic study shows disruption of numerous cytoskeleton-associated proteins, the dysregulation in F-actin is of primary importance to the axon defects observed in $D c x^{-l y}$; Dclk1 ${ }^{-1-}$ mutant neurons. Our study also shows that the defect in Dcx/Dclk1 deficiency in growth cones is in axon guidance without a change in elongation. This phenomenon is similar to the effect of pharmacological agents that preferentially depolymerize F-actin (Marsh and Letourneau, 1984; Bentley and Toroian-Raymond, 1986; Chien et al., 1993; Lafont et al., 1993; Kaufmann et al., 1998; Dent and Kalil, 2001). In addition, studies have shown that animal models with targeted deletions of actin regulatory proteins have axon guidance defects (Dent et al., 2011). In contrast, disruption or knockdown of some of the other candidate proteins from the Dcx proteomic screen, such as Tau, have no axonal guidance defects (Harada et al., 1994; Tint et al., 1998; Dawson et al., 2001). While we recognize that a wide range of cell biology is affected by Dcx/Dclk1 deficiency and that these processes are important for axon guidance, a severe defect in actin regulation is sufficient to explain the axonal phenotype in these mutants.

In vitro data have demonstrated Dcx-mediated actin bundling via spinophilin (Tsukada et al., 2003; Bielas et al., 2007); however, the functional significance of this finding had not been demonstrated in neurons. Our data show that the loss of Dcx results in a marked decrease of F-actin structures, lamellipodia and filopodia in growth cones, which correlates with the in vitro studies on Dcx/spinophilin. Significantly, this finding suggests an "inside out" regulation of growth cone turning where signals that modulate Dcx/MT binding result in actin polymerization and the formation of lamellipodia and filopodia in a spatially directed manner. This regulation, in addition to the more canonical model of actin recruitment of microtubules into regions of growth, is likely responsible for the exquisite pathfinding ability of axonal growth cones.

Alternatively, the interaction of Dcx with spinophilin to crosslink actin and microtubules may be related to other Dcx functions. We have recently shown that Dcx regulates molecular motors at the microtubule (Liu et al., 2012). Since Dcx MT binding is at its highest levels in the distal growth cone, the ability of Dcx to bundle actin may function as a way to coordinate transport functions in elongating processes. Thus, Dcx may regulate the "hand off" or transition between microtubule-based transport via kinesins and actin-based transport functions via myosin, thus, insuring the successful journey of cargo through the actin domain of elongating axons and the arrival of vesicles at the cell membrane. We will investigate these hypotheses for Dcx regulation of actin in our future studies, including testing Dcx for effects on myosin, the actin-based motor.

\section{References}

Bechstedt S, Brouhard GJ (2012) Doublecortin recognizes the 13protofilament microtubule cooperatively and tracks microtubule ends. Dev Cell 23:181-192. CrossRef Medline

Bentley D, Toroian-Raymond A (1986) Disoriented pathfinding by pioneer neurone growth cones deprived of filopodia by cytochalasin treatment. Nature 323:712-715. CrossRef Medline

Bielas SL, Serneo FF, Chechlacz M, Deerinck TJ, Perkins GA, Allen PB, Ellisman MH, Gleeson JG (2007) Spinophilin facilitates dephosphorylation of doublecortin by PP1 to mediate microtubule bundling at the axonal wrist. Cell 129:579-591. CrossRef Medline

Bloom O, Unternaehrer JJ, Jiang A, Shin JS, Delamarre L, Allen P, Mellman I (2008) Spinophilin participates in information transfer at immunological synapses. J Cell Biol 181:203-211. CrossRef Medline

Chien CB, Rosenthal DE, Harris WA, Holt CE (1993) Navigational errors made by growth cones without filopodia in the embryonic Xenopus brain. Neuron 11:237-251. CrossRef Medline

Coquelle FM, Levy T, Bergmann S, Wolf SG, Bar-El D, Sapir T, Brody Y, Orr I, Barkai N, Eichele G, Reiner O (2006) Common and divergent roles for members of the mouse DCX superfamily. Cell Cycle 5:976-983. CrossRef Medline

Creppe C, Malinouskaya L, Volvert ML, Gillard M, Close P, Malaise O, Laguesse S, Cornez I, Rahmouni S, Ormenese S, Belachew S, Malgrange B, Chapelle JP, Siebenlist U, Moonen G, Chariot A, Nguyen L (2009) Elongator controls the migration and differentiation of cortical neurons through acetylation of alpha-tubulin. Cell 136:551-564. CrossRef Medline

Dawson HN, Ferreira A, Eyster MV, Ghoshal N, Binder LI, Vitek MP (2001) Inhibition of neuronal maturation in primary hippocampal neurons from tau deficient mice. J Cell Sci 114:1179-1187. Medline

Dent EW, Kalil K (2001) Axon branching requires interactions between dynamic microtubules and actin filaments. J Neurosci 21:9757-9769. Medline

Dent EW, Gupton SL, Gertler FB (2011) The growth cone cytoskeleton in axon outgrowth and guidance. Cold Spring Harb Perspect Biol 3:pii: a001800. CrossRef Medline

des Portes V, Francis F, Pinard JM, Desguerre I, Moutard ML, Snoeck I, Meiners LC, Capron F, Cusmai R, Ricci S, Motte J, Echenne B, Ponsot G, Dulac O, Chelly J, Beldjord C (1998) doublecortin is the major gene causing X-linked subcortical laminar heterotopia (SCLH). Hum Mol Genet 7:1063-1070. CrossRef Medline

Deuel TA, Liu JS, Corbo JC, Yoo SY, Rorke-Adams LB, Walsh CA (2006) Genetic interactions between doublecortin and doublecortin-like kinase in neuronal migration and axon outgrowth. Neuron 49:41-53. CrossRef Medline

Edlund M, Lotano MA, Otey CA (2001) Dynamics of alpha-actinin in focal adhesions and stress fibers visualized with alpha-actinin-green fluorescent protein. Cell Motil Cytoskeleton 48:190-200. CrossRef Medline

Friocourt G, Chafey P, Billuart P, Koulakoff A, Vinet MC, Schaar BT, McConnell SK, Francis F, Chelly J (2001) Doublecortin interacts with mu subunits of clathrin adaptor complexes in the developing nervous system. Mol Cell Neurosci 18:307-319. CrossRef Medline

Gleeson JG, Allen KM, Fox JW, Lamperti ED, Berkovic S, Scheffer I, 
Cooper EC, Dobyns WB, Minnerath SR, Ross ME, Walsh CA (1998) Doublecortin, a brain-specific gene mutated in human X-linked lissencephaly and double cortex syndrome, encodes a putative signaling protein. Cell 92:63-72. CrossRef Medline

Gleeson JG, Lin PT, Flanagan LA, Walsh CA (1999) Doublecortin is a microtubule-associated protein and is expressed widely by migrating neurons. Neuron 23:257-271. CrossRef Medline

Hammond JW, Cai D, Verhey KJ (2008) Tubulin modifications and their cellular functions. Curr Opin Cell Biol 20:71-76. CrossRef Medline

Harada A, Oguchi K, Okabe S, Kuno J, Terada S, Ohshima T, Sato-Yoshitake R, Takei Y, Noda T, Hirokawa N (1994) Altered microtubule organization in small-calibre axons of mice lacking tau protein. Nature 369:488491. CrossRef Medline

Hu J, Bai X, Bowen JR, Dolat L, Korobova F, Yu W, Baas PW, Svitkina T, Gallo G, Spiliotis ET (2012) Septin-driven coordination of actin and microtubule remodeling regulates the collateral branching of axons. Curr Biol 22:1109-1115. CrossRef Medline

Jensen ON, Wilm M, Shevchenko A, Mann M (1999) Sample preparation methods for mass spectrometric peptide mapping directly from 2-DE gels. Methods Mol Biol 112:513-530. Medline

Kappeler C, Dhenain M, Phan Dinh Tuy F, Saillour Y, Marty S, Fallet-Bianco C, Souville I, Souil E, Pinard JM, Meyer G, Encha-Razavi F, Volk A, Beldjord C, Chelly J, Francis F (2007) Magnetic resonance imaging and histological studies of corpus callosal and hippocampal abnormalities linked to doublecortin deficiency. J Comp Neurol 500:239-254. CrossRef Medline

Kaufmann N, Wills ZP, Van Vactor D (1998) Drosophila Racl controls motor axon guidance. Development 125:453-461. Medline

Koizumi H, Tanaka T, Gleeson JG (2006) Doublecortin-like kinase functions with doublecortin to mediate fiber tract decussation and neuronal migration. Neuron 49:55-66. CrossRef Medline

Lafont F, Rouget M, Rousselet A, Valenza C, Prochiantz A (1993) Specific responses of axons and dendrites to cytoskeleton perturbations: an in vitro study. J Cell Sci 104:433-443. Medline

Liu G, Beggs H, Jürgensen C, Park HT, Tang H, Gorski J, Jones KR, Reichardt LF, Wu J, Rao Y (2004) Netrin requires focal adhesion kinase and Src family kinases for axon outgrowth and attraction. Nat Neurosci 7:12221232. CrossRef Medline

Liu JS, Schubert CR, Fu X, Fourniol FJ, Jaiswal JK, Houdusse A, Stultz CM, Moores CA, Walsh CA (2012) Molecular basis for specific regulation of neuronal kinesin-3 motors by doublecortin family Proteins. Mol Cell 47:707-721. CrossRef Medline

Marsh L, Letourneau PC (1984) Growth of neurites without filopodial or lamellipodial activity in the presence of cytochalasin B. J Cell Biol 99: 2041-2047. CrossRef Medline

Ming GL, Song HJ, Berninger B, Holt CE, Tessier-Lavigne M, Poo MM (1997) cAMP-dependent growth cone guidance by netrin-1. Neuron 19: 1225-1235. CrossRef Medline

Moores CA, Perderiset M, Francis F, Chelly J, Houdusse A, Milligan RA
(2004) Mechanism of microtubule stabilization by doublecortin. Mol Cell 14:833-839. CrossRef Medline

Moores CA, Perderiset M, Kappeler C, Kain S, Drummond D, Perkins SJ, Chelly J, Cross R, Houdusse A, Francis F (2006) Distinct roles of doublecortin modulating the microtubule cytoskeleton. EMBO J 25: 4448-4457. CrossRef Medline

Santra M, Santra S, Roberts C, Zhang RL, Chopp M (2009) Doublecortin induces mitotic microtubule catastrophe and inhibits glioma cell invasion. J Neurochem 108:231-245. CrossRef Medline

Schaar BT, Kinoshita K, McConnell SK (2004) Doublecortin microtubule affinity is regulated by a balance of kinase and phosphatase activity at the leading edge of migrating neurons. Neuron 41:203-213. CrossRef Medline

Spillane M, Ketschek A, Jones SL, Korobova F, Marsick B, Lanier L, Svitkina T, Gallo G (2011) The actin nucleating Arp $2 / 3$ complex contributes to the formation of axonal filopodia and branches through the regulation of actin patch precursors to filopodia. Dev Neurobiol 71:747-758. CrossRef Medline

Stevanin G, Santorelli FM, Azzedine H, Coutinho P, Chomilier J, Denora PS, Martin E, Ouvrard-Hernandez AM, Tessa A, Bouslam N, Lossos A, Charles P, Loureiro JL, Elleuch N, Confavreux C, Cruz VT, Ruberg M, Leguern E, Grid D, Tazir M, et al. (2007) Mutations in SPG11, encoding spatacsin, are a major cause of spastic paraplegia with thin corpus callosum. Nat Genet 39:366-372. CrossRef Medline

Tint I, Slaughter T, Fischer I, Black MM (1998) Acute inactivation of tau has no effect on dynamics of microtubules in growing axons of cultured sympathetic neurons. J Neurosci 18:8660-8673. Medline

Tint I, Jean D, Baas PW, Black MM (2009) Doublecortin associates with microtubules preferentially in regions of the axon displaying actin-rich protrusive structures. J Neurosci 29:10995-11010. CrossRef Medline

Tsukada M, Prokscha A, Oldekamp J, Eichele G (2003) Identification of neurabin II as a novel doublecortin interacting protein. Mech Dev 120: 1033-1043. CrossRef Medline

Tsukada M, Prokscha A, Ungewickell E, Eichele G (2005) Doublecortin association with actin filaments is regulated by neurabin II. J Biol Chem 280:11361-11368. CrossRef Medline

Vidal CN, Nicolson R, DeVito TJ, Hayashi KM, Geaga JA, Drost DJ, Williamson PC, Rajakumar N, Sui Y, Dutton RA, Toga AW, Thompson PM (2006) Mapping corpus callosum deficits in autism: an index of aberrant cortical connectivity. Biol Psychiatry 60:218-225. CrossRef Medline

Wells CM, Ridley AJ (2005) Analysis of cell migration using the Dunn chemotaxis chamber and time-lapse microscopy. Methods Mol Biol 294:31-41. Medline

Yam PT, Langlois SD, Morin S, Charron F (2009) Sonic hedgehog guides axons through a noncanonical, Src-family-kinase-dependent signaling pathway. Neuron 62:349-362. CrossRef Medline

Zicha D, Dunn G, Jones G (1997) Analyzing chemotaxis using the Dunn direct-viewing chamber. Methods Mol Biol 75:449-457. Medline 